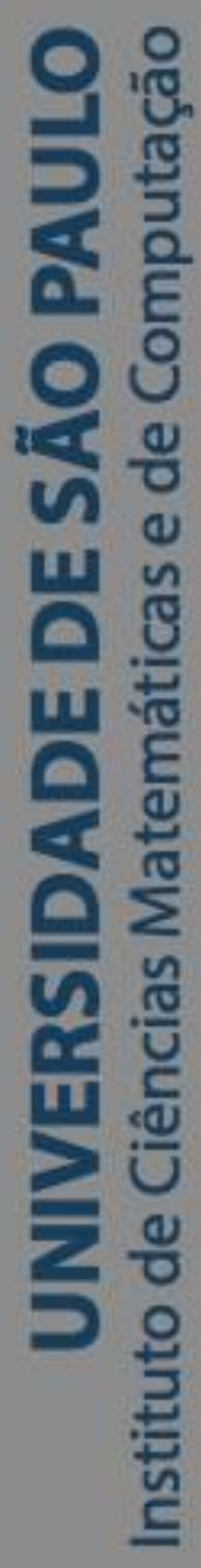

\title{
Números: algumas atividades lúdicas
}

\section{Denis Gomes Lima}

Dissertação de Mestrado do Programa de Mestrado

Profissional em Matemática em rede Nacional (PROFMAT) 
SERVIÇO DE PÓS-GRADUAÇÃO

DO ICMC-USP

Data de Depósito:

Assinatura:

\title{
Denis Gomes Lima
}

Números: algumas atividades lúdicas

\begin{abstract}
Dissertação apresentada ao Instituto de Ciências Matemáticas e de Computação - ICMC-USP, como parte dos requisitos para obtenção do título de Mestre em Ciências - Mestrado Profissional em Matemática em Rede Nacional. VERSÃO REVISADA

Área de Concentração: Mestrado Profissional em Matemática em Rede Nacional

Orientadora: Profa. Dra Rosana Retsos Signorelli Vargas
\end{abstract}


Ficha catalográfica elaborada pela Biblioteca Prof.

Achille Bassi e Seção Técnica de Informática,

ICMC/USP,

com os dados inseridos pelo(a) autor(a)

L732n Lima, Denis Gomes Lima

Gomes Lima Lima; orientador Rosana Retsos

Signorelli Vargas Vargas. -- São Carlos, 2018.

$89 \mathrm{p}$.

Dissertação (Mestrado - Programa de Pós-Graduação em Mestrado Profissional em Matemática em Rede Nacional) -- Instituto de Ciências Matemáticas e de Computação, Universidade de São Paulo, 2018.

1. 1. Atividades lúdicas.. 2. 2. Congruências..

3. 3. Diversas abordagens de ensino.. 4. 4. Números inteiros.. 5. 5. Mudanças no ensino.. I. Vargas, Rosana Retsos Signorelli Vargas, orient. II. Título.

Bibliotecários responsáveis pela estrutura de catalogação da publicação de acordo com a AACR2: Gláucia Maria Saia Cristianini - CRB - 8/4938 


\title{
Denis Gomes Lima
}

\section{Numbers: some playful activities}

\author{
Master dissertation submitted to the Institute of \\ Mathematics and Computer Sciences - ICMC- USP, in \\ partial fulfillment of the requirements for the degree of \\ Mathematics Professional Master's Program. FINAL \\ VERSION \\ Concentration Area: Professional Master Degree \\ Program in Mathematics in National Network \\ Advisor: Profa. Dra Rosana Retsos Signorelli Vargas
}

\section{USP - São Carlos}

July 2018 
A minha família. 


\section{Agradecimentos}

À Deus e a Nossa Senhora Aparecida por ter a mim concebido sabedoria, saúde e força durante toda caminhada de desafios, dificuldades e alegrias.

À minha família, esposa Luana Aparecida Pereira Lima e filhos Fabrício Aparecido Pereira Lima, Amanda Aparecida Pereira Lima, que nos momentos de dificuldades foram motivos de perseverança aos meus ideais, aos meus sonhos.

À minha orientadora Dra. Rosana Retsos Signorelli Vargas, que durante todo o desenvolvimento desse trabalho me ajudou nos apontamentos e correções em breves ou duradouras discussões.

Aos meus amigos de curso e aos meus professores que tanto me auxiliaram em minhas dúvidas e dificuldades.

Aos meus pais Maria Lucia Gomes dos Santos e Deraldo Ferreira Lima que com tanto carinho e simplicidade me ajudaram a me tornar o homem de hoje. 
O sucesso nasce do querer, da determinação e persistência em se chegar a um objetivo.

- José de Alencar - 


\section{RESUMO}

LIMA, D. G. Números: algumas atividades lúdicas. 2018 89p. Dissertação (Mestrado em Matemática - Mestrado Profissional em Matemática em Rede Nacional) - Instituto de Ciências Matemáticas e de Computação, Universidade de São Paulo, São Carlos - SP, 2018.

Diante da atual situação da aprendizagem no país, nos capítulos que seguem desse trabalho, discutiremos que é possível mudarmos esse quadro através dos métodos de ensino. Abordamos especialmente a divisão, a multiplicação e as frações. Analisamos a evolução dos números desde sua origem até o atual padrão usado assim como as propriedades dos números inteiros, seguido da discussão de números racionais e congruências que permitem que a divisão e a multiplicação sejam operações usáveis e de fácil compreensão. Finalizamos nossas pesquisas com um capítulo voltado a atividades lúdicas que possam ser aproveitadas em projetos e laboratório de matemática.

Palavras-chave: Divisão, multiplicação, fração, laboratórios. 


\section{ABSTRACT}

LIMA, D. G. Numbers: Some playful activities. 2018. 89p. Dissertation (Master in mathematics - Master's degree in mathematics in national network) - Institute of mathematical and computing sciencias. University of São Paulo, São Carlos - SP, 2018.

Before present situation of the learning in the country, near chapter this work, discuss what is possible to chance this picture through teaching methods. Broach especially the division, multiplication, and the fraction. We analyze the evolution of the numbers since its origin until the present model used, like this how analysis the property in the whole numbers, followed, of the discussion of rational numbers and congruences what permit the division and the multiplication are operation usual and of easy understandable. We finished our research, with a chapter think the playful activities what own be take in project and laboratory of mathematics.

Keywords: division, multiplication, fracion, laboratory.. 


\section{SUMÁRIO}

INTRODUÇÃO

Mudanças no ensino com laboratório de matemática e projetos......................... 12

1 ASPECTOS HISTÓRICOS.................................................................... 16

1.1 O surgimento da matemática sobre a Terra.................................................. 16

1.2 Bases e o surgimento do contrato.......................................................... 17

1.3 Alguns sistemas de numeração:............................................................. 19

1.3.1 Sistema de numeração Babilônico....................................................... 19

1.3.2 Sistema de numeração dos Egípcios...................................................... 19

1.3.3 Números Romanos............................................................................ 19

1.3.4 Sistema de numeração Grego.......................................................... 19

1.3.5 Numerais Hindo - Arábico ............................................................... 20

1.3.6 Sistema de numeração decimal......................................................... 20

2 NÚMEROS NATURAIS..............................................................................

2.1 A axiomática de G. Peano................................................................ 21

3 NÚMEROS INTEIROS..................................................................... 27

3.1 Uma fundamentação axiomática............................................................... 27

3.2 O princípio da indução completa............................................................ 33

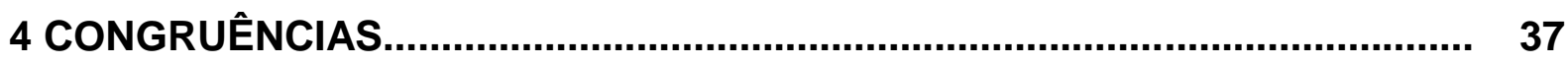

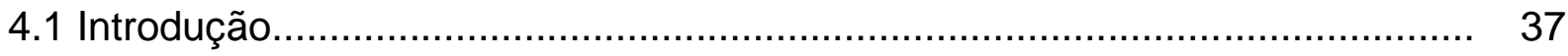

4.2 Aplicação da definição de congruência.................................................... 37

4.3 Propriedades operatória das congruências............................................... 38

5 NÚMEROS RACIONAIS..................................................................... 42

5.1 Construção, operação e relação de ordem............................................... 42

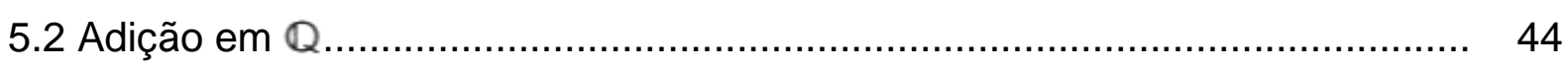

5.3 Multiplicação em Q...................................................................... 46

6 ATIVIDADES E LABORATÓRIOS........................................................ 50

6.1 Divisão e fração......................................................................... 50

6.1.1 Frações equivalentes ao inteiro..................................................... 50

6.1.2 Frações de diferentes denominadores equivalentes................................. 51

6.1.3 Frações impróprias.......................................................................... 52

6.1.4 Divisão usada pelos egípcios............................................................. 54

6.1.5 Trabalhando com o número 1....................................................... 56 
6.1.6 O calendário e a divisão.................................................................... 58

6.1.7 Problemas. Razão........................................................................ 60

6.1.8 Divisão por 9. (truque).................................................................... 61

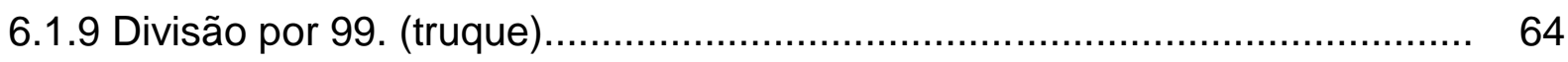

6.1.10 Frações e divisões como partilha.......................................................... 67

6.2 Multiplicação .................................................................................. 69

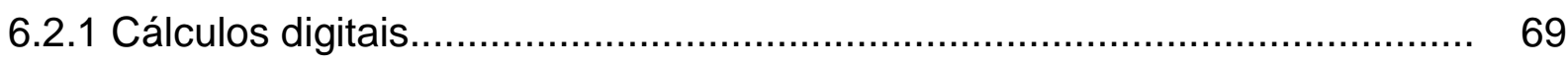

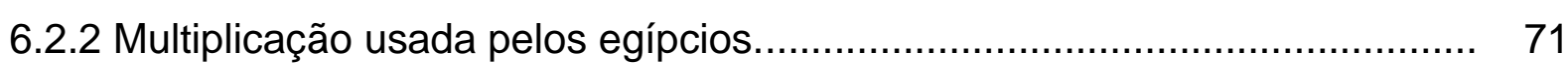

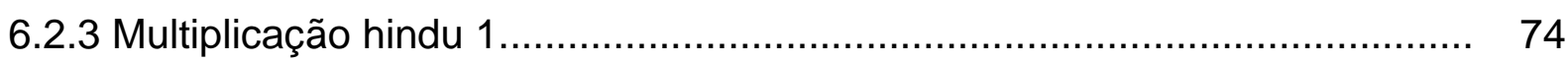

6.2.4 Multiplicação hindu 2 ................................................................... $\quad 75$

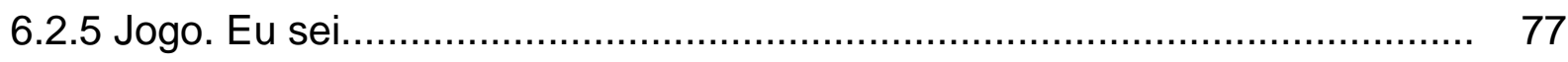

7 APLICAÇÕES DE ATIVIDADES.............................................................. 79

7.1 Descrições das atividades......................................................................... 79

7.1.1 Desenvolvimento da aplicação............................................................ 79

7.1.2 Atividade realizada pelos alunos do $1^{\circ}$ ano............................................. 80

7.1.3 Atividade realizada pelos alunos do $8^{\circ}$ ano........................................... 82

8 CONCLUSÕES....................................................................................... 86

REFERÊNCIAS BIBLIOGRÁFICAS........................................................ 87 


\section{Introdução}

\section{Mudanças no ensino com laboratório de matemática e projetos}

É consensual a idéia de que não existe um caminho que possa ser identificado como único e melhor para o ensino de qualquer disciplina, em particular, da matemática. No entanto, conhecer diversas possibilidades de trabalho em sala de aula é fundamental para que o professor construa sua prática. [3]

Diante de tantas dificuldades e barreiras, precisamos encontrar caminhos que desperte o interesse em estudar e a vontade de aprender. É constatado que o ensino tradicional, onde o professor expõe idéias, técnicas e exemplos, e logo depois o aluno é desafiado a resoluções de exercícios não é tão eficiente e produtivo. A necessidade de mudanças no ensino de matemática exige novas formas e meios de ensino para que ela se torne atrativa e prazerosa aos alunos e é claro que podemos aproveitar o tradicional com as devidas adaptações [10].

O aprendizado para muitos alunos acontece através das diversas formas concretas, por esse motivo a eficácia do material didático na aprendizagem é incontestável, sejam eles dos mais simples (revistas, jornais, panfletos, palitos,...) aos mais sofisticados (softwares, notebooks,...) [7]. Assim já defendido por estudiosos segundo Locke [8] (apud Lorenzato 2010, p.3) "A necessidade da experiência sensível para alcançar o conhecimento" e segundo Piaget [8] (apud Lorenzato 2010, p.4) "O conhecimento se dá pela ação refletiva de objetos".

Nessas últimas décadas, muitos estudiosos da área do ensino de matemática vêm discutindo, propondo e criando métodos didáticos e jogos para melhoria do ensino, pois o aprender matemática precisa deixar de ser extremamente abstrato e ceder lugar a situações concretas que dão sentido à matemática a ser aprendida.

Também existem professores, que individualmente ou em pequenos grupos, têm iniciativas para buscar novos conhecimentos e assumem uma atitude de constante reflexão, que os leva a desenvolver práticas pedagógicas mais eficientes para ensinar matemática. De modo semelhante, universidades, secretarias de educação e outras instituições têm produzido materiais de apoio para a prática do professor. [3] 
Figura 1.1: Material dourado (recurso pedagógico)

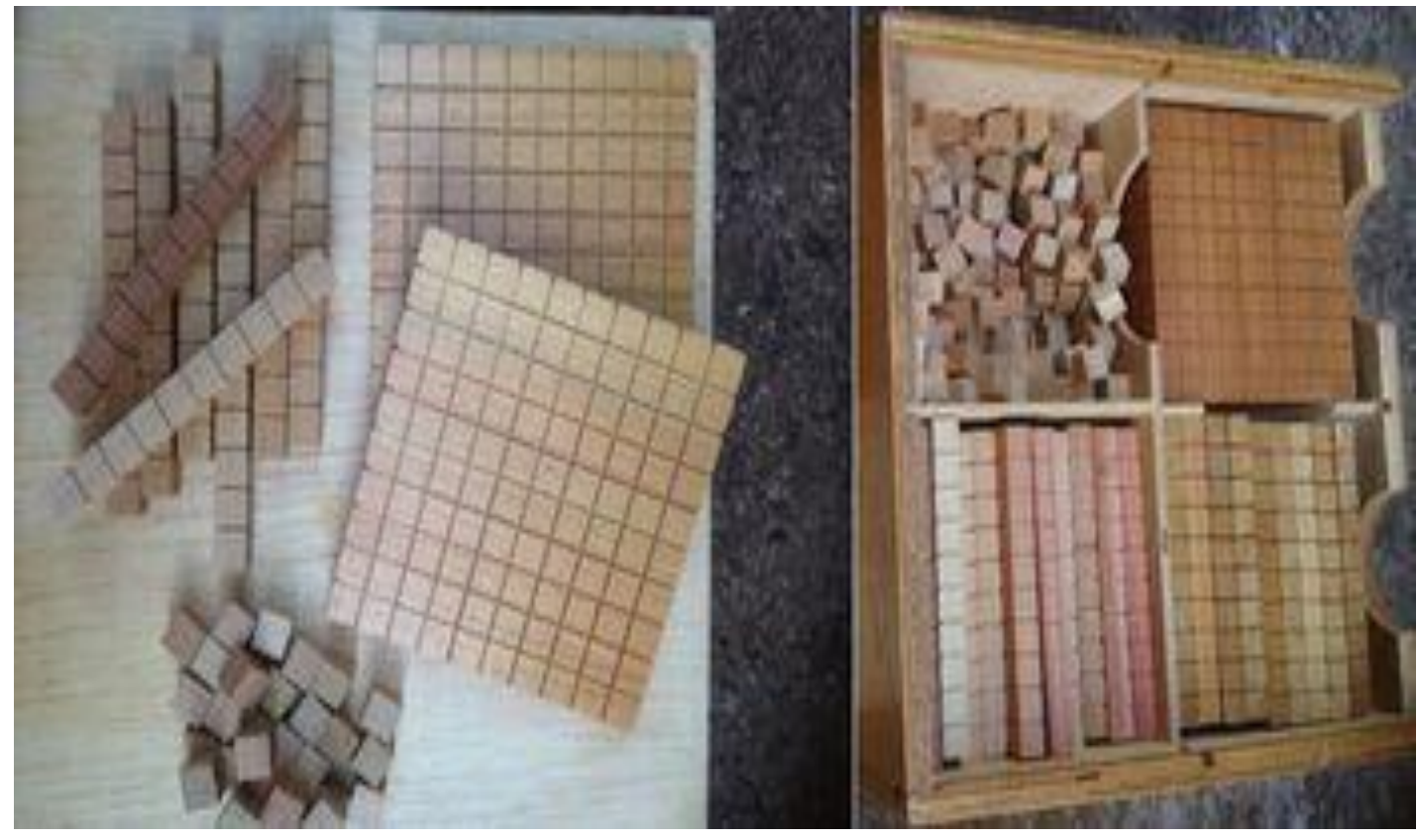

Fonte: Disponível em http: // professoraivaniferreira.blogspot.com

A figura 1.1 nos trás a imagem de um possível recurso didático dentre tantos que serão citados e discutidos no texto abaixo.

Em meio às diversas abordagens de ensino que se diferencia do método tradicional, um desafio é a presença de laboratórios de matemática, ou seja, o desenvolvimento de atividades de matemática que abordem o concreto e desafiem o raciocínio lógico dedutivo do aluno. Isso exige do professor muita pesquisa, estudos e observações para que com muito cuidado as atividades sejam adaptadas de acordo com idade, ano/série e condições sociais do aluno. Para o desenvolvimento do laboratório de matemática, há uma quantidade considerável de recursos a disposição do professor como: livros didáticos, livros paradidáticos, artigos, jornais, panfletos, problemas, questões de vestibular, questões do Enem, prova Brasil, jogos, figuras, calculadoras, computadores, softwares, filmes, veja também figura 1.1: material dourado. 
Figura 1.2: Laboratório de matemática.

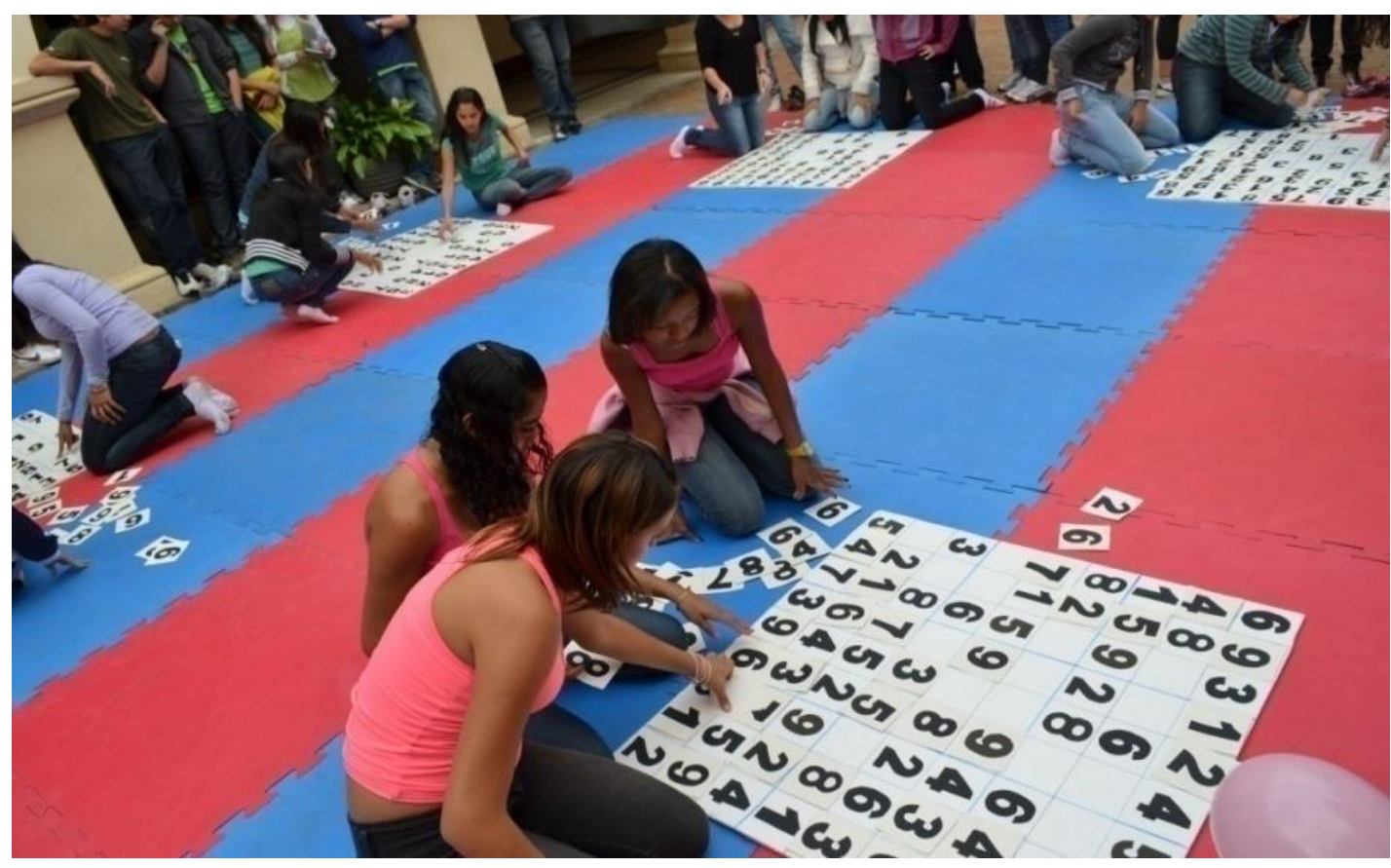

Fonte: http://www.noticiasantigas.mg.gov.br

Notemos na figura 1.2 que o laboratório de matemática pode ocupar diferentes ambientes dentro da unidade escolar, sala de informática, sala de aula, pátio, quadra, jardim, sala de vídeo, sempre buscando estratégias e meios que coloquem em destaque uma forma nova e atraente de aprender. O laboratório de matemática é um trabalho desafiador a ser desenvolvido em longo prazo, é necessário que o professor esteja atento para que em momentos nos quais a aprendizagem não esteja acontecendo, o trabalho seja inovado com atividades que retomem o objetivo.

Tornar o saber matemático acumulado um saber escolar, possível de ser ensinado/aprendido, exige que esse conhecimento seja transformado, pois a obra e o pensamento do matemático teórico geralmente são difíceis de serem comunicados diretamente aos alunos. Essa consideração implica rever a idéia, que persiste na escola, de ver nos objetos de ensino cópias fiéis dos objetos da ciência. [3]

Outra abordagem de ensino significante é o desenvolvimento de projetos. Inicialmente é necessária a criação de um acordo que seja discutido com os alunos prevendo seus deveres e seus direitos podendo ser alterado a qualquer momento, desde que seja com a finalidade de criar novas regras para valorizar o aprendizado. Durante a execução de um projeto os alunos enfrentarão situações reais ou 
próximas da realidade, onde eles terão como dever interpretar/entender a matemática e aprender com as situações propostas pelo professor. Tomamos como exemplos de atividades próximas da realidade e atividades coerentes com situações reais: a construção de uma casa, as dimensões da escola, o percurso casa/escola, ou até uma compra realizada na sorveteria. A partir da situação escolhida, desafiamos o aluno a determinar variáveis referentes à situação proposta e cabe ao professor planejar e propor esses desafios. Defendido pelas idéias de Piaget [2] (1969, apud Bordenave e Pereira, p.28 à p.31), "as inteligências é algo que se vai construindo gradualmente pela estimulação e os desafios".

$\mathrm{Na}$ área de matemática, não podemos confundir pinturas de figuras, recorte de figuras e jornais, colagem de cartazes com um projeto de matemática. $\mathrm{O}$ projeto deve contemplar atividades que façam os alunos refletirem sobre situações reais ou próximas da realidade, provocando construção de conhecimento.

O capítulo 1 mostra a criação do sistema numérico decimal ao longo dos anos, como também as barreiras que retardaram seu desenvolvimento. A evolução das diversas bases e sistemas de numeração, acompanhado de discussões que mostraram como e por que foram criados. Os capítulos 2, 3 e 5 abordam os conceitos, propriedades e as operações com números naturais, números inteiros e números racionais justificando e apoiando as atividades lúdicas discutidas nesse trabalho. No capítulo 4 apresentamos as definição de congruência, algumas observações importantes e proposições que podem ajudar a resolver problemas. $O$ capítulo 6 traz sugestões de atividades e laboratórios que podem ser aproveitadas por docentes no exercício de suas funções, como também dá base à criações de atividades similares que busquem o conhecimento usando o lúdico. Finalmente, no capítulo 7 apresentando algumas aplicações de atividades desenvolvidas durante as pesquisas. 


\section{Capítulo 1}

\section{Aspectos Históricos}

\subsection{O surgimento da matemática sobre a Terra}

$\mathrm{Na}$ construção desse texto tivemos como referência [6]. Somente a espécie humana foi capaz de registrar e acumular informações que foram transmitidas, melhoradas e aprimoradas de geração a geração e assim também aconteceu com os conhecimentos matemáticos. Ainda temos tribos indígenas que não dominam esses registros (de cálculos), porém, sabemos que muitas delas indicam as quantidades como 1 e 2, e acima disso elas apenas indicam que há muitos ou vários. Registros mostram que nossos antepassados foram todos assim e foi difícil o caminho para chegarmos onde estamos. No início contávamos para indicar quantidade de caça, produção agrícola, criação de animais, de forma bem simples, pois plantávamos, criávamos animais e caçávamos apenas para suprir nossas necessidades [6].

Figura 2.1: formas de contagem.

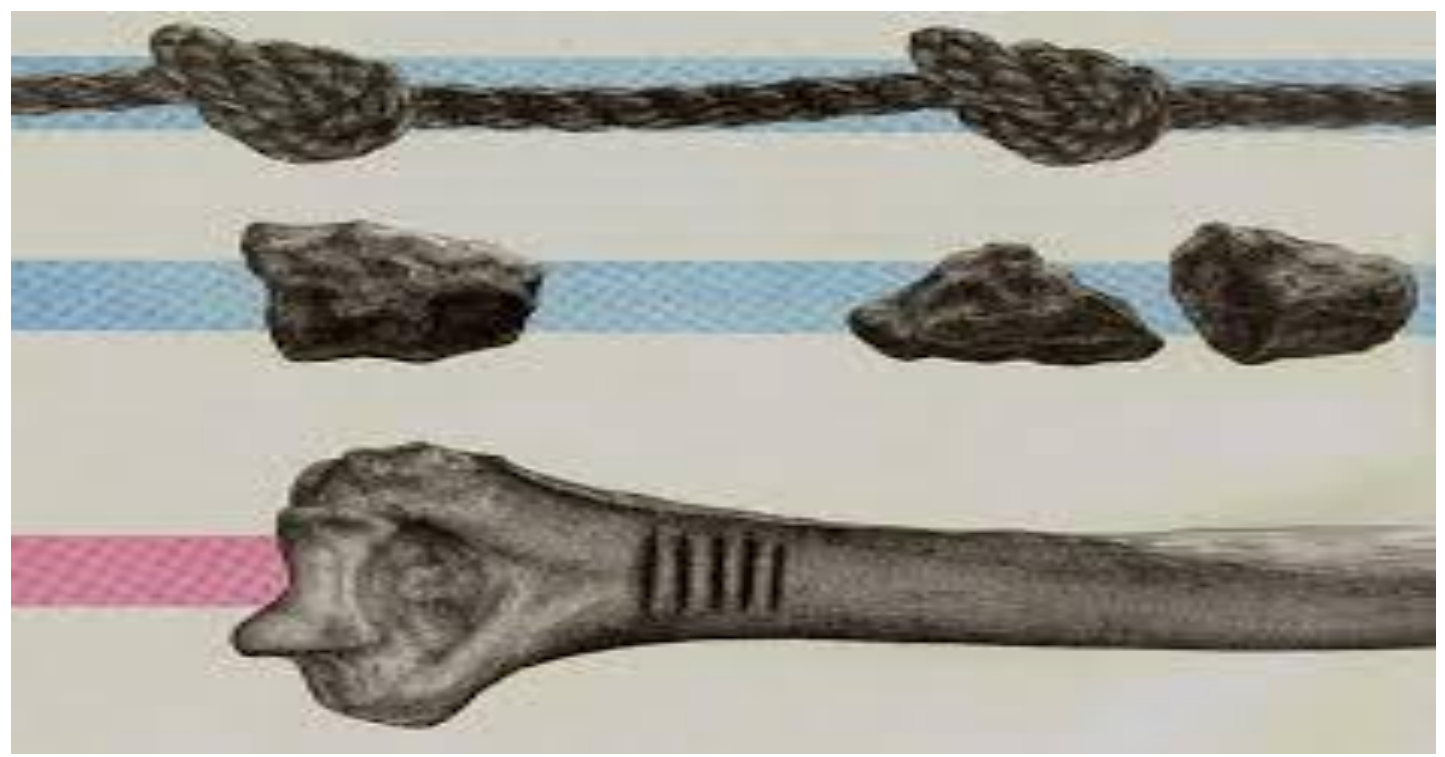

Fonte: http://www.matematicaefacil.com.br

Os primeiros registros deixados sobre a Terra, não se referem a nenhuma forma de escrita, mas à forma de contagem por ranhuras em rochas, contagem de um a um por meio de pedras, uso das partes do corpo, entalhos em madeiras, nós em corda, etc... , "Veja na figura 2.1 algumas formas de registros utilizadas antes da criação dos números". 
Levou-se muito tempo até o desenvolvimento de uma escrita capaz de representar algarismos e palavras, pois foram inúmeras barreiras que retardaram o desenvolvimento da matemática, desde simples superstições (não era permitido contar crianças e ovelhas, pois estariam atraindo lobos que as comeriam), até as imposições mais complexas (proibições da igreja, proibições dos reis,...) tudo fazia com que descobertas e criações importantes se perdessem ou não fossem divulgadas, como resultado os conhecimentos retornavam ao seu estado inicial ou ficavam parados por décadas e décadas.

Os bugilai da Nova Guiné contavam usando membros do corpo sempre na mesma sequência, um pouco mais tarde as partes do corpo passaram a receber nome, essa associação a um nome facilitava, pois não havia mais a necessidade de fazer tal representação através da sequência de toques, dessa forma um número pela primeira vez foi associada a uma palavra.

As várias formas de contar foram surgindo sobre a Terra em diferentes bases de numeração: base 5 , base 10 , base 12 , base 20 , base 60 , números romanos, números egípcios, números chineses, todos suprindo as necessidades de escritas e contagem de diversos povos da antiguidade. É lógico que o desenvolvimento das diferentes bases e dos números duraram muitos anos, séculos ou até milênios. A verdade é que muitos desses sistemas se mostraram inconvenientes por se tratarem de sistemas posicionais incompletos. Nesse caso estou me referindo à ausência do zero, registros históricos mostram que ele apareceu ainda antes de Cristo, e o reconhecimento dele como algarismo aconteceu no período de 500 D.C a 1100 D.C pelos matemáticos Hindus e Árabes, muito provável que foi na tentativa de apresentar solução para funções quadráticas, onde uma raiz é zero ou estudos sistemáticos das propriedades das operações de números.

\subsection{Bases e o surgimento do contrato.}

BASE 5 - registros indicam que um dos principais motivos do seu desenvolvimento é de nossas mãos terem cinco dedos, contando-se até o cinco em uma de suas mãos e havendo a necessidade poderia voltar a contar usando a outra mão. [13]

BASE 10 - registros mostram que o desenvolvimento dessa base se deve ao uso dos 10 dedos para contar. [13] 
BASE 12 - registros mostram que o desenvolvimento se deu por contarem as falanges dos dedos das mãos com exceção dos dedos polegares. [13]

BASE 20 e BASE 60 - não há registros que expliquem o motivo pelo qual tribos adotaram e desenvolveram essas bases. [13]

A base 60 foi descoberta na Suméria por volta do ano 3500 A.C. Esses povos representavam seu sistema de numeração através de símbolos (cones, bolinhas e esferas). Ainda na mesma época Elamitas também desenvolveram um sistema de numeração que usava base 10 e base 60. Essa forma de contagem era representada através de símbolos (cones, bastões, esferas e discos) é nessa época que surgem os primeiros contratos que temos registros, eles eram confeccionados em dois tabletes de argila, onde as combinações dos desenhos e dos símbolos deram origem a primeira escrita. "Veja na figura 2.2 um contrato em tablete de argila". Os registros e as escritas surgiram e foram aperfeiçoados com o crescimento do comércio, quando as trocas de mercadorias tornaram-se mais intensas, nesse momento não bastavam apenas palavras entre aqueles que negociavam e realizavam trocas, e dessa forma foram criados os símbolos para registrar as trocas.

Figura 2.2: plimpton 322.

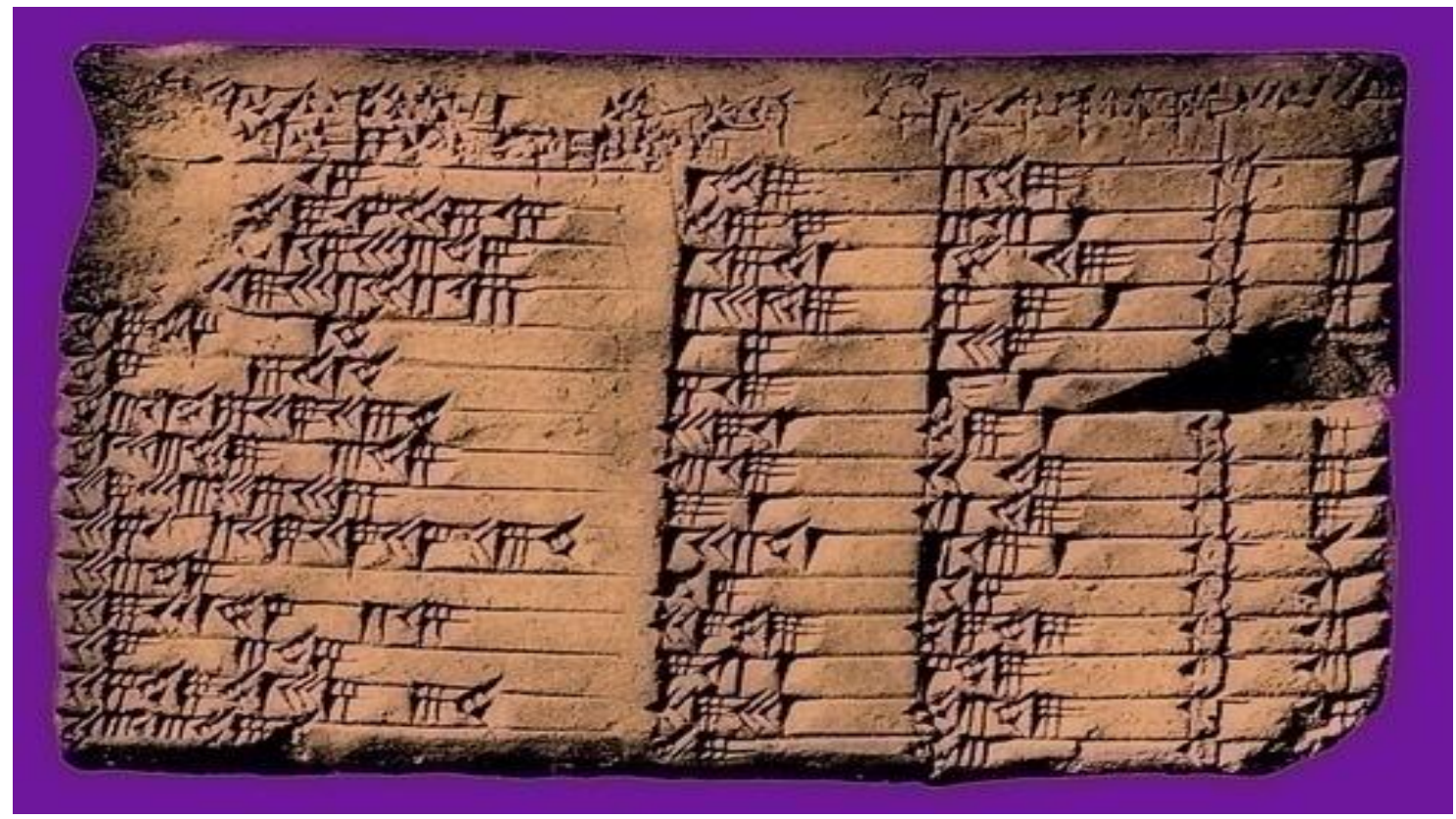

Fonte: http://www.historiaecuriosidadesmatematicas.blogspot.com

Se entre dois homens ficasse firmado a seguinte troca: Lhe dou dois cavalos, cinco sacos de arroz e dois sacos de feijão e em troca quero um boi, três peles e 
dois carneiros, tudo era registrado em dois tabletes de argila como da figura 2.2, assinado por ambos e só seriam quebradas quando as trocas se concretizassem.

\subsection{Alguns sistemas de numeração:}

1.3.1 Sistema de numeração babilônico. Em 2000 anos A.C. os babilônios já haviam desenvolvido seu sistema de numeração que emprega o princípio posicional de base 10 e base 60 , onde havia um símbolo para unidade e um símbolo para dezena, após o 59 a unidade era posicionada a se tornar 60 , apesar dos babilônios não terem criado uma forma de registro ao zero na escrita de seus números, um espaço em branco era deixado para a potência de 60 ausentes, ainda assim em algumas situações os significados dos números eram muito confusos. A origem e o motivo do uso da base 60 pelos babilônios são desconhecidos, mas sua utilização é notável na circunferência de $360^{\circ}$, nas horas, nos minutos e segundos [5].

1.3.2 Sistema de numeração dos Egípcios. Em 3400 anos A.C., os egípcios já haviam desenvolvido os primeiros hieróglifos para representar seu sistema de numeração de base 10. Eles não adotaram um símbolo para o zero, mas seu sistema é composto de vários símbolos, onde o bastão representa as unidades, ou seja, os números de 1 à 9 , o arco as dezenas e a flor de lótus as centenas, conforme a necessidade de números maiores serem escritos, novas representações eram criadas e incluídas no sistema de numeração [5].

1.3.3 Números Romanos. Não se tem registro que confirmem a origem das formas que representam esse sistema de numeração, apesar de ainda utilizados em algumas situações. Os números romanos deixaram de ser utilizados em vários setores a partir do ano de 1300 D.C., com o argumento que esses numerais eram de fácil falsificação [5].

1.3.4 Sistema de Numeração Grego. Os gregos criaram diversas representações numéricas, destacam se entre eles o sistema de numeração Ático usado 600 anos A.C. e o Jônico usado 200 anos A.C. No sistema Ático eram usados I para $1, \Gamma$ para $5, \Delta$ para $10, \mathrm{H}$ para 100 , x para 1000 , M para 10000 , onde pelo principio aditivo seus números eram apresentados. O sistema Jônico era de base dez, princípio aditivo e formado por 27 letras sendo 24 do alfabeto Grego e 3 do alfabeto Fenício, divididos em três classes de 9 símbolos cada, onde a primeira 
classe representava os algarismos das unidades, a segunda as dezenas e a terceira as centenas [5].

1.3.5 Numerais Hindo Arábicos. Têm-se registros que por volta do ano 250 A.C., os povos Hindus já haviam desenvolvido seu sistema de numeração composto por nove algarismos posicionais de escritas diferentes dos atuais. Ainda nessa época não havia nenhum símbolo para o zero. Por volta do ano 800 D.C., essa forma de contagem já tinha sido adotado pelos árabes, que após dominarem e reconhecerem como eficiente e conveniente, disseminaram-no por outras partes do mundo [5].

1.3.6 Sistema de numeração decimal. Os números que usamos diariamente estamos aqui os abordando e discutindo seus processos de divisão, eles fazem parte de um sistema decimal posicional de algarismos $0,1,2,3,4,5,6$, $7,8,9$, ou seja, dependendo da posição ocupada eles representarão valores diferentes [9].

Nas discussões anteriores, vimos que esses algarismos surgiram com os povos Hindus e foram disseminados pelo planeta por intermédio dos povos árabes, que após estudar e compreender essa geniosa invenção dividiu seus conhecimentos com os povos que naquela época tinham contato. Agora vamos verificar a definição.

A definição de base pode ser traduzida como a quantidade de elementos definida para efetuarmos agrupamentos, ou seja, para qualquer número inteiro e positivo, este admite uma única representação $N$.

Dizemos que $N=a_{k} \cdot a_{k-1} \ldots . a_{1} \cdot a_{0}$ é um número escrito na base $p \geq 2$.

Podemos escrever $N$ como soma de potências de $p$ na forma:

$N=a_{k} p^{k}+a_{k-1} p^{k-1}+\ldots+a_{1} p^{1}+a_{0}$, com $0 \leq a_{i} \leq p-1$.

Em particular, $N$ está escrito na base 10 quando $p=10$, ou seja:

$N=a_{k} 10^{k}+a_{k-1} 10^{k-1}+\ldots+a_{1} 10^{1}+a_{0}$.

Tomamos como exemplo:

$N=1327$, então: $N=1 \cdot 10^{3}+3 \cdot 10^{2}+2 \cdot 10^{1}+7$.

$N=486$, então: $N=4 \cdot 10^{2}+8 \cdot 10^{1}+6$. 
$N=39$, então: $N=3 \cdot 10^{1}+9$.

Note que qualquer dos números Hindo Arábico por nós usados, pode ser escrito com essa formação. 


\section{Capítulo 2}

\section{Números Naturais}

\subsection{A axiomática de G. Peano.}

$\mathrm{Na}$ construção desse capítulo tomamos como referência [9]. Os números naturais podem ser apresentados como um conjunto cuja existência admitimos que vale num reduzido número de axiomas. O método de Giuseppe Peano se baseia no fato de que os números naturais podem ser ordenados numa sequência, na qual cada elemento tem um "sucessor" bem definido, por causa disso diz-se uma teoria ordinal. Outra fundamentação possível seria construir uma teoria cardinal, isto é, formalizar a idéia intuitiva - que foi também a primeira a ser concedida - de que o número expressa quantidade.

Em 1879, Peano na sua fundamentação admitiu três conceitos primitivos: Número natural, zero e sucessor, relacionados entre si por cinco axiomas. Indicaremos por $\sigma(x)$ o "sucessor" do número $x$ e, como é usual, utilizaremos o símbolo 0 para indicar o zero.

Com essas notações, os axiomas são os seguintes:

(1) 0 é um número natural.

(2) Todo número natural $x$ tem um "sucessor" $\sigma(x)$.

(3) 0 não é "sucessor" de nenhum número.

(4) Se $\sigma(x)=\sigma(y)$, então $x=y$.

(5) Princípio da indução completa: Seja $S$ um conjunto de números naturais tal que:

(a) $0 \in S$

(b) Se $x \in S$, então $\sigma(x) \in S$.

Então, $S$ é o conjunto de todos os números naturais.

Denotaremos por IN o conjunto dos números naturais.

O conceito primitivo de sucessor nada mais é do que uma função, que a cada número associa outro; o axioma 2 apenas afirma que uma função está definida em todo IN.

Admitiremos, então que existe um conjunto $1 \mathrm{~N}$ e uma função $\sigma: I N \rightarrow I N$ verificando:

$P .1$ Existe um elemento $0 \in \mathbb{N}$ tal que $0 \notin \operatorname{Im}(\sigma)$. 
P.2 A função $\sigma$ é injetora.

$P .3$ Seja $A$ um conjunto de IN tal que:

(i) $0 \in A$

(ii) Se $x \in A$, então $\sigma(x) \in A$.

Então, $A=\mathrm{IN}$.

Indicaremos por $\mathrm{IN}^{+}$o conjunto de todos os naturais diferentes de zero. Note que $\sigma(0) \in \mathrm{IN}^{+}$e, conforme o axioma $P .2$, temos que $0 \neq \sigma(0)$, isso mostra que $1 \mathrm{~N}^{+}$é não vazio.

Ainda, podemos provar que todo natural diferente de zero é sucessor de algum número.

\subsubsection{Proposição}

$$
\operatorname{Im}(\sigma)=\mathbb{I N}^{+}
$$

\section{Demonstração:}

Basta considerar o conjunto $A=\{0\} \cup \operatorname{Im}(\sigma)$. Obviamente, $0 \in A$ e se $x \in A$ então $\sigma(x) \in A$ (pois $\sigma(x) \in \operatorname{Im}(\sigma))$.

Logo, pelo axioma $P .3, A=\mathrm{IN}$. Assim, dado um natural $x \in \mathrm{IN}$, como $x \in A$ e $x \neq 0$, devemos ter $x \in \operatorname{Im}(\sigma)$.

\subsubsection{Definição.}

Dado um natural $x \neq 0$, o número natural y tal que $\sigma(y)=x$ chama-se $o$ antecessor de $x$, e $x$ chama-se o sucessor de $y$.

\section{Exemplo:}

Para o elemento $x=2$, o sucessor de $x$ definido por $\sigma(x)$ será $\sigma(2)=3$. Daí, então 2 é o antecessor e 3 é o sucessor.

Mostraremos que podemos definir as operações de adição e multiplicação. Começaremos por definir a adição, queremos dar um significado aos símbolos $y+x$, para todo par de números $x, y \in \mathbb{I N}$. Para isso procederemos em duas etapas: Primeiro consideraremos um $y$ fixo e indicaremos o que entendemos por $y+x$ para qualquer $x \in \mathrm{IN}$ e depois, verificaremos que a adição está bem definida para todo par de números naturais. 


\subsubsection{Definição.}

Seja $y \in \mathbb{I N}$ um número natural dado. Então:

(i) $y+0=y$.

(ii) $y+\sigma(x)=\sigma(y+x)$.

Note que sabemos somar y com 0 e que a segunda condição nos permite somar y com o sucessor de 0 , com o sucessor do sucessor de 0 etc.

\subsubsection{Proposição}

Seja $y \in \mathbb{I N}$ um número natural dado. Então, a adição $y+x$ está definida para todo número natural $x \in \mathbb{I N}$

\section{Demonstração:}

Seja $A$ o conjunto de naturais $n$ para os quais as soma $m+n$ está definida.

Conforme a condição (i) da definição anterior, temos que $0 \in A$, e da condição (ii) temos que, se $y+x$ está definido, então $y+\sigma(x)$ também está definido ou, em símbolo, se $x \in A$, então $\sigma(x) \in A$.

Do axioma de indução temos que $A=I N$ e segue a tese.

Notamos agora que, para cada $y \in \mathbb{I N}$ sabemos que a adição $y+x$ está definida para todo natural $x \in \mathbb{I N}$, o que quer dizer que $y+x$ está definido para todo par de números naturais $y, x$.

Ou seja, elaborar toda a teoria a partir dos axiomas de Peano não passa de um longo exercício de indução.

\subsubsection{Proposição}

Para toda terna $x, y, z$ de números naturais, vale:

$$
x+(y+z)=(x+y)+z
$$

\section{Demonstração:}

Seja $S$ o conjunto dos números naturais $z$ tais que $x+(y+z)=(x+y)+z$, para todo par de naturais $x, y$. Para demonstrar a proposição, bastará provar que $S=\mathbb{I N}$.

Temos que:

$$
x+(y+0)=x+y=(x+y)+0 .
$$


Logo, $0 \in S$.

Ainda, suponhamos que $z \in S$, isto é, que $x+(y+z)=(x+y)+z$

Vamos provar que também $\sigma(z) \in S$. Com efeito, $x+(y+\sigma(z))=x+\sigma(y+z)=\sigma(x+(y+z))=\sigma((x+y)+z)=(x+y)+\sigma(z)$.

Tivemos que usar aqui, repetidamente, a condição (ii) da definição 2.1.3. $\square$

\subsubsection{Proposição}

Para todo número natural $x$, tem-se que $x+0=x=0+x$.

\section{Demonstração:}

A primeira igualdade segue da própria definição.

Para provar a segunda igualdade, consideramos o conjunto dos naturais $A=\{x \in \mathrm{IN} / 0+x=x\}$.

Obviamente, $0 \in A$.

Ainda, se $0+x=x$, temos que $0+\sigma(x)=\sigma(0+x)=\sigma(x)$, logo, verifica-se também a partir de (ii) do axioma $P .3$, e temos que $A=\mathbb{I N}$.

Ainda precisaríamos demonstrar que 0 é o único elemento neutro, pois a priori, nada impede que algum outro natural $u$ verifique $u+x=x+u=x$, para todo $x$.

\subsubsection{Proposição}

O neutro aditivo é único.

\section{Demonstração:}

Seja $u$ um elemento neutro, e consideremos a soma $0+u$.

Como $u$ é neutro, por hipótese, temos $0+u=0$.

Ainda, como provamos que o 0 é neutro, temos também $0+u=u$. Logo, $0=u$. 
Para evitar algumas dificuldades na demonstração da propriedade comutativa, introduziremos primeiro o elemento 1.

\subsubsection{Definição}

Indicaremos por 1 o número natural que é o sucessor de 0 , isto é, $1=\sigma(0)$.

\subsubsection{Proposição}

Para todo natural $x$, tem-se que $\sigma(x)=1+x$.

\section{Exemplo:}

a) $\sigma(0)=1+0$, então $\sigma(0)=1$.

b) $\sigma(1)=1+1$, então $\sigma(1)=2$. Veja também que $\sigma(\sigma(0))=\sigma(1)=2$

c) $\sigma(2)=1+2$, então $\sigma(2)=3$ e $\sigma(\sigma(\sigma(0)))=\sigma(2)=3$

Note que após uma sucessiva repetição desse processo teremos um conjunto A formado pelos seus sucessores.

\section{Demonstração:}

Seja $A=\{x \in \mathrm{IN} / \sigma(x)=1+x\}$.

Obviamente, $0 \in A$, pois $\sigma(0)=1+0=1$.

Seja, então, $x \in A$. Mostraremos que $\sigma(x) \in A$.

Com efeito, como $\sigma(x)=1+x$, temos que:

$\sigma(\sigma(x))=\sigma(1+x)=1+\sigma(x)$, isto é $\sigma(x) \in A$.

Do axioma $P .3$, temos que $A=\mathrm{IN}$.

\subsubsection{Proposição}

Para todo par $x, y$ de números naturais, tem-se que $x+y=y+x$.

\section{Demonstração:}

Mais uma vez, usaremos uma técnica semelhante àquela das proposições anteriores. Consideremos o conjunto

$$
A=\{x \in \mathrm{IN} / x+y=y+x, \forall y \in \mathbb{I N}\} .
$$


Da proposição 2.1.6 temos que $0 \in A$.

Seja então $x \in A$. Provaremos que também $\sigma(x) \in A$. Com efeito, temos:

$y+\sigma(x)=\sigma(y+x)=\sigma(x+y)=1+x+y=\sigma(x)+y$

Assim, do axioma $P .3$ segue, mais uma vez, que $A=\mathrm{IN}$.

A definição de produto será feita de forma análoga à soma.

\subsubsection{Definição}

Seja $x \in \mathbb{I N}$ um natural dado. Então:

$x .0=0$.

$x . \sigma(y)=x \cdot y+x$.

\section{Observação:}

Essa definição de produto de números naturais satisfaz as propriedades associativa, comutativa e distributiva.

\subsubsection{Definição}

Sejam $x$ e $y$ números naturais. Diremos que $x$ é menor ou igual a $y$ se existir outro número natural $r$ tal que $x+r=y$.

Em símbolos,

$x \leq y$ se existir $r \in \mathbb{I N}$ tal que $x+r=y$.

Segue que a definição 2.1 .12 servirá de base para provar os axiomas $A .12$, A.13 e A.14 que serão apresentados no próximo capítulo. 


\section{Capítulo 3}

\section{Números Inteiros}

Assim como discutimos no capítulo 1, a noção de números naturais desenvolveu-se gradativamente a partir das necessidades e das experiências cotidianas, o mesmo não aconteceu com os números inteiros negativos. O primeiro uso conhecido desses números encontra-se na obra indiana atribuída a Brahmagupta (628 anos D. C.) onde são interpretados como dívidas.

Nesse capítulo apresentaremos as propriedades elementares através de uma fundamentação axiomática do conjunto dos números inteiros, o princípio da boa ordem e o princípio da indução finita. Para isso usaremos como base [9].

\subsection{Uma fundamentação axiomática}

$\mathrm{Na}$ construção desse capítulo tomamos como referência [9]. Os números inteiros formam um conjunto, que denotaremos por $\mathbb{Z}$, no qual estão definidas duas operações, que chamaremos de adição e multiplicação e denotaremos por + e • . $E m \mathbb{Z}$ também está definida uma relação que permite comparar os seus elementos, a relação "menor ou igual", que indicaremos por $\leq$.

Para não sermos excessivamente formais, não definiremos aqui os conceitos de operação e relação; limitar-nos-emos a usá-los no seu sentido intuitivo.

Os axiomas que passaremos a detalhar descreverão algumas das propriedades básicas das operações e da relação "menor ou igual", que tomaremos como base para desenvolver a teoria. Qualquer outra propriedade, mesmo que intuitivamente óbvia, poderá ser demonstrada a partir dessas.

A.1 Propriedade Associativa: Para toda terna $x, y, z$ de inteiros tem-se que $x+(y+z)=(x+y)+z$.

A.2 Existência do neutro: Existe um único elemento, denominado neutro aditivo ou zero, que indicaremos por 0 , tal que

$x+0=x$, para todo $x \in \mathbb{Z}$.

A.3 Existência do oposto: Para cada inteiro $x$ existe um único elemento que chamaremos oposto de $x$ e indicaremos por $-x$, tal que

$$
x+(-x)=0
$$


A.4 Propriedade comutativa: Para todo par $x, y$ de inteiros tem-se que $x+y=y+x$.

O próximo grupo de axiomas explicita algumas das propriedades da multiplicação.

A.5 Propriedade Associativa: Para toda terna $x, y, z$ de inteiros tem-se que $x \cdot(y \cdot z)=(x \cdot y) \cdot z$.

A.6 Existência do neutro: Existe um único elemento, diferente de zero, denominado neutro multiplicativo, que indicaremos por 1 , tal que

$1 . a=a$, para todo $a \in \mathbb{Z}$.

A.7 Propriedade cancelativa: Para toda terna $x, y, z$ de inteiros, com $x \neq 0$ tem-se que, se $x . y=x . z$, então, $y=z$.

A.8 Propriedade comutativa: para todo par $x, y$ de inteiros, tem-se que $x \cdot y=y \cdot x$

Comparando o grupo de axiomas dados para a adição e a multiplicação, percebe-se uma grande semelhança entre ambos. A única diferença notável surge entre os axiomas $A .3$ e A.7. Um análogo a $A .3$ para multiplicação afirmaria que para todo $x \in \mathbb{Z}$ existe um elemento, digamos, $x^{\prime} \in \mathbb{Z}$ tal que $x . x^{\prime}=1$. Sabemos, porém, que isso não acontece: quando $x=2$, por exemplo, não existe nenhum inteiro $x^{\prime}$ tal que $2 x^{\prime}=1$.

3.1.1 Proposição (Propriedade cancelativa da adição)

Para toda terna $x, y, z$ de inteiros tem-se que:

Se $x+y=x+z$, então $y=z$.

\section{Demonstração:}

Se $x+y=x+z$, somando o oposto de $x$ a ambos os membros dessa igualdade, temos que:

$$
(-x)+(x+y)=(-x)+(x+z) .
$$

Usando a propriedade associativa, temos: 
$[(-x)+(x)]+y=[(-x)+(x)]+z$.

Isto é,

$0+y=0+z$

Portanto,

$y=z$.

O próximo axioma relaciona ambas as operações.

A.9 Propriedade distributiva: Para toda terna $x, y, z$ de inteiros tem-se que $x \cdot(y+z)=x \cdot y+x \cdot z$.

As próximas afirmações também são intuitivamente evidentes, mas conforme o plano inicial será demonstrado com base nos axiomas até aqui introduzidos.

\subsubsection{Proposição}

Para todo inteiro $x$, tem-se que $x .0=0$.

\section{Demonstração:}

Como $x .0+x .0=x .(0+0)=x .0=x .0+0$, comparando o primeiro e o último termo da cadeia de igualdade acima temos que

$x .0+x .0=x .0+0$.

Usando a propriedade cancelativa da adição, vem imediatamente que $x .0=0$.

\subsubsection{Proposição}

Sejam $x, y$ inteiros, tais que $x \cdot y=0$. Então, $x=0$ ou $y=0$.

\section{Demonstração:}

Se $x \cdot y=0$, usando a proposição anterior podemos escrever essa igualdade na forma $x \cdot y=x .0$.

Se $x=0$, a proposição está demonstrada. Se $x \neq 0$, podemos usar o axioma A.7 para cancelar e obtermos $y=0$. 


\subsubsection{Proposição (Regra de sinais)}

Sejam $x$ e y inteiros. Então vale:

(i) $-(-x)=x$.

(ii) $(-x) \cdot(y)=-(x \cdot y)=x(-y)$.

(iii) $(-x) \cdot(-y)=x \cdot y$.

\section{Demonstração:}

Notamos inicialmente que podemos interpretar o axioma $A .3$ da seguinte forma: o oposto de um elemento $x$ é o único inteiro que verifica a equação $x+a=0$.

Para provar (i) basta observar que $x$ verifica a equação $(-x)+x=0$. Conseqüentemente, $x$ é o oposto de $-x$ (que é o elemento indicado por $-(-x)$ ).

Para provar a primeira igualdade de (ii), basta observar que $(-x) \cdot y$ é a solução de $x \cdot y+a=0$, já que $x \cdot y+(-x) \cdot y=[(-x)+x] \cdot y=0 \cdot y=0$.

Analogamente, verifica-se que $x \cdot y+x \cdot(-y)=0$.

Para (iii), podemos observar diretamente que aplicando (ii) temos $(-x) \cdot(-y)=-(x \cdot(-y))=-(-(x \cdot y))$, e usando (i) no último termo segue que $(-x) \cdot(-y)=x \cdot y$.

A.10 Propriedade reflexiva: Para todo inteiro $x$ tem-se que $x \leq x$.

A.11 Propriedade anti-simétrica: Dados dois números inteiros $x$ e $y$, se $x \leq y$ e $y \leq x$, então $x=y$.

A.12 Propriedade transitiva: Para toda terna $x, y, z$ de inteiros tem-se que, se $x \leq y$ e $y \leq z$, então $x \leq z$.

Por causa dos axiomas A.10, A.11 e $A .12$ diz-se que a relação $\leq$ é uma relação de ordem.

Usaremos o símbolo $x<y$ para indicar $x \leq y$, mas $x \neq y$; nesse caso, diremos que $x$ é menor que $y$. No que segue, empregaremos o termo "positivo" e "negativo" no seu sentido usual, isto é, para indicar que um certo número é maior ou 
menor que zero, respectivamente. Quando convenientemente, usaremos também os símbolos $y \geq x$ ou $y>x$ para indicar que $x \leq y$ ou $x<y$.

A.13 Tricotomia: Dados dois números inteiros quaisquer $x$ e $y$ tem-se que ou $x<y$ ou $x=y$ ou $y<x$.

Devemos ainda introduzir alguns axiomas que vinculem a relação de ordem com as operações:

A.14 Para toda terna $x, y, z$ de inteiros, se $x \leq y$, então $x+z \leq y+z$.

A.15 Para toda terna $x, y, z$ de inteiros, se $x \leq y$ e $0 \leq z$ então $x . z \leq y \cdot z$.

Note que, no nosso sistema de axioma, admite-se que $1 \neq 0$, porém, não sabemos ainda se $0<1$ ou $1<0$.

\subsubsection{Proposição}

Seja $x$ um inteiro. Então:

(i) Se $x \leq 0$. Então $-x \geq 0$.

(ii) Se $x \geq 0$. Então $-x \leq 0$.

(iii) $x^{2} \geq 0$ (Isto é, na terminologia usual, todo quadrado é não negativo).

(iv) $1>0$.

\section{Demonstração:}

Se $x \leq 0$, usando o axioma A.14 podemos somar $-x$ a ambos os membros e temos $(-x)+x \leq(-x)+0$, isto é, $0 \leq-x$.

A demonstração de (ii) é análoga.

Para provar (iii) discutiremos separados dois casos. Se $x \geq 0$, podemos, usando A.15, multiplicar ambos os membros dessa desigualdade por $x$ e obtemos diretamente $x . x \geq 0 . x$, isto é, $x^{2} \geq 0$. Se $x \leq 0$, de (i) vem que $-x \geq 0$. Da parte anterior temos que $(-x)^{2} \geq 0$ e da parte (iii) da proposição 3.1 .4 vem que $(-x)^{2}=x^{2} ; \log 0 x^{2} \geq 0$.

Finalmente, como $1=1^{2}$, (iv) segue imediatamente de (iii) . 


\subsubsection{Definição}

Seja A um subconjunto de $\mathbb{Z}$. Diz-se que A é limitado inferiormente se existe algum inteiro $k$ tal que, para todo $x \in A$, tem-se que $k \leq x$.

Um elemento $x_{0} \in A$ diz-se elemento mínimo de $A$ se, para todo $x \in A$, temse que $x_{0} \leq x$ (verifica-se que, se existe um elemento mínimo de $A$, ele é único).

De forma análoga define-se conjunto limitado superiormente e elemento máximo do conjunto $A$, quando existirem.

A.16 Princípio da boa ordem: Todo conjunto não-vazio de inteiros nãonegativos contém um elemento mínimo.

Note que, como conseqüência dos axiomas $A .14$ e $A .15$, podemos provar que $0<1$. Porém, ainda não conseguimos demonstrar o fato óbvio de que não existem inteiros entre 0 e 1. Esse é o conteúdo da próxima proposição.

\subsubsection{Proposição}

Seja $x$ um inteiro tal que $0 \leq x \leq 1$. Então, $x=0$ ou $x=1$.

\section{Demonstração:}

Suponhamos por absurdo que exista um inteiro $x$ diferente de 0 e 1 nessas condições. Assim, o conjunto $S=\{x \in \mathbb{Z} / 0<x<1\}$ seria não-vazio e pelo Princípio da Boa Ordem existiria $m=\min S$.

Como $m \in S$ temos que $m>0$ e $m<1$. Usando o axioma $A .15$, multiplicando por $m$ a segunda desigualdade, obtemos $m^{2}<m$. Assim, $m^{2}>0$ e, como $m<1$, da propriedade transitiva temos $m^{2}<1$. Logo, $m^{2} \in S$ e é menor que seu elemento mínimo, uma contradição.

\subsubsection{Proposição (Propriedade Arquimediana)}

Sejam $x$ e y inteiros positivos. Então, existe um inteiro positivo $n$ tal que $n \cdot x>y$.

\section{Demonstração:}

Suponhamos que a afirmação não seja verdadeira. Isso significa que, para todo inteiro positivo $n$, tem-se que $y \geq n . x$. Assim, o conjunto 
$S=\{y-n x / n \in \mathbb{Z}, \quad n>0\}, \quad$ está formado por inteiros não-negativos. Conforme o princípio da Boa Ordem existe $m=\min S$. Como $m \in S$, ele é da forma $m=y-r x$ para algum $r \in \mathbb{Z}$.

Consideramos então o elemento $m^{\prime}=y-(r+1) \cdot x$, que também pertence a $S$, e temos $m^{\prime}=y-(r+1) \cdot x=(y-r . x)-x=m-x<m$ (pois $\left.x>0\right)$.

Teríamos, então, que $m^{\prime} \in S$ e $m^{\prime}<m=\min S$, uma contradição.

Note que, trivialmente, se um conjunto $A$ tem um mínimo então $A$ é limitado inferiormente. A recíproca também é verdadeira, como demonstraremos a seguir.

\subsubsection{Proposição}

Todo conjunto não-vazio de inteiros limitados inferiormente tem mínimo.

\section{Demonstração:}

Seja $A$ tal conjunto e seja ainda $k \in \mathbb{Z}$ tal que, para todo $x \in A$, tem-se que $k \leq x$. Consideramos então o conjunto $S=\{x-k / x \in A\}$.

Obviamente, $S \neq \phi$, já que $A$ é não vazio. E, como $k \leq x$, para todo $x \in A$, os elementos de $S$ são não-negativos. Do princípio da boa ordem, existe $m=\min S$, que será da forma $m=x_{0}-k$, para algum $x_{0} \in A$. Mostraremos que o elemento $x_{0}$ assim determinado é o mínimo de $A$.

Como $x_{0}$ é um elemento de $A$, só resta verificar que, para todo $x \in A$, tem-se que $x_{0} \leq x$. Suponhamos que isso não aconteça. Assim, existe $x_{1} \backslash$ inA. Tal que $x_{1}<x_{0}$. Somando $-k$ a ambos os membros, $x_{1}-k<x_{0}-k=m$. Teríamos exibido, assim, um elemento de $S$ menor que $m=\min S$, uma contradição.

\subsection{O Princípio de Indução Completa}

As ciências naturais utilizam o método chamado indução empírica para formular leis que devem reger determinados fenômenos a partir de um grande número de observações particulares, selecionadas adequadamente. Esse tipo de procedimento, embora não seja uma demonstração de que um dado fato é logicamente verdadeiro, é freqüentemente satisfatório. Por exemplo: Quando um 
corpo caí sob a ação da gravidade na superfície da Terra, ele descreve uma trajetória vertical.

A validade de um teorema matemático se estabelece de forma totalmente diferente. Verificar que uma certa afirmação é verdadeira num grande número de casos particulares não nos permitirá concluir que ela é válida.

Com efeito, dada a expressão $\phi(n)=n^{2}-n+41$, consideremos a seguinte afirmação: para cada inteiro positivo $n$, o valor de $\phi(n)$ é um número primo.

Para $n=1$ temos que $\phi(1)=41$. Da mesma forma, $\phi(2)=43, \phi(3)=47 \mathrm{e}$ com um pouco de paciência poderá verificar que a afirmação é verdadeira para os primeiros 40 valores de $n$. Porém, para $n=41$ temos que $\phi(41)=41.41$, que não é um número primo.

Consideremos então uma afirmação como a seguinte: a soma dos $n$ primeiros inteiros positivos é igual a $\frac{n(n+1)}{2}$, ou em símbolos, $1+2+3+\ldots+n=\frac{n(n+1)}{2}$

Como verificar sua validade? Evidentemente, é impossível demonstrá-la em todos os casos particulares.

Para demonstrar a verdade desse tipo de proposição, que na realidade é uma sequência infinita de proposições, uma para cada inteiro positivo, introduziremos o chamado método de recorrência ou indução completa.

\subsubsection{Teorema}

Sejam $x$ um inteiro dado e $S$ um conjunto de inteiros maiores ou iguais a $x$, que tem as seguintes propriedades:

(i) $x \in S$.

(ii) Se um inteiro $k \geq x$ pertence a $S$, então $k+1$ também pertence a $S$.

Então $S$ é o conjunto de todos inteiros maiores ou iguais a $x$. 


\section{Demonstração:}

Suponha que a afirmação seja falsa. Então, o conjunto $S^{\prime}$ dos inteiros maiores ou iguais a $x$ que não pertencem a $S$ é não-vazio (e limitado inferiormente por $x$ ). Conforme a proposição 3.1.9, existe $m=\min S^{\prime}$.

Como $a \in S$, certamente $a<m$, logo $a \leq m-1<m$. Temos ainda que $m-1<m=\min S^{\prime}, \log 0 m-1 \notin S^{\prime}$, isto é, $m-1 \in S$. Conforme (ii), teremos então que $m=(m-1)+1 \in S$, uma contradição, já que $m \in S^{\prime}$.

\subsubsection{Corolário (Princípio da indução completa - 1ª forma)}

Seja $x$ um inteiro dado. Suponhamos que para cada inteiro $n \geq x$ está dada uma afirmação $A(n)$ de forma que:

(i) $A(x)$ é verdadeira.

(ii) Se para um inteiro $k \geq x, A(k)$ é verdadeira, então $A(k+1)$ é verdadeira.

Então a afirmação $A(n)$ é verdadeira para todo inteiro $n \geq x$.

\section{Demonstração:}

Basta considerar o conjunto $S$ dos inteiros $n \geq x$ para os quais $A(n)$ é verdadeira e verificar que está nas condições do teorema anterior. Assim, $S$ contém todos os inteiros maiores ou iguais a $x$ e segue a tese.

Exemplo:

Provaremos agora que a fórmula $1+2+\ldots+n=\frac{n(n+1)}{2}$ é verdadeira para todo $n \geq 1$.

Para $n=1$, a fórmula acima dá $1=\frac{1 \cdot(1+1)}{2}$, isto é, $1=1$.

Assim, nossa afirmação é verdadeira para $n=1$. Deveremos mostrar agora que, se a afirmação é verdadeira para $n=k$, então também é verdadeira para $n=k+1$.

Estamos admitindo, então, como verdadeiro que $1+2+\ldots+k=\frac{k(k+1)}{2}$. 
Somando $k+1$ a ambos os membros dessa igualdade temos $1+2+\ldots+k+(k+1)=\frac{k(k+1)}{2}+(k+1)=\frac{k(k+1)+2(k+1)}{2}$.

Isto é,

$1+2+\ldots+k+(k+1)=\frac{(k+1) \cdot(k+2)}{2}$ que é a fórmula correspondente a $n=k+1$, cuja validade queríamos demonstrar.

\subsubsection{Teorema}

Sejam $x$ um inteiro dado e $S$ um conjunto de inteiros maiores ou iguais a $x$, que tem as seguintes propriedades:

(i) $x \in S$.

(ii) Se $k$ é um inteiro maior ou igual a $x$ tal que todo inteiro $m$ verificando $x \leq m \leq k$ pertence a $S$, então $k+1$ pertence a $S$.

Então, $S$ é o conjunto de todos inteiros maiores ou iguais a $x$.

\section{Demonstração:}

Suponhamos que a afirmação seja falsa. Então, o conjunto $S^{\prime}$ dos inteiros maiores ou iguais a $x$, que não pertence a $S$, é não-vazio e limitado inferiormente. Conforme a proposição 3.1 .9 , existe $m_{0}=\min S^{\prime}$, e pela condição (i) certamente $m_{0}>x, \log 0 m_{0}-1 \geq x$.

Como $m_{0}$ é o menor elemento de $S^{\prime}$, podemos concluir que os inteiros $x, x+1, \ldots, m_{0}-1$ todos pertencem a $S$. Logo, aplicando a condição (ii) para $k=m_{0}-1$, temos que $\left(m_{0}-1\right)+1=m_{0}$ pertence a $S$; uma contradição. 


\section{Capítulo 4}

\section{Congruência}

\subsection{Introdução}

$\mathrm{Na}$ construção desse capítulo tomamos como referências [9]. O estudo das congruências é voltado para o resto das divisões e o ensino tradicional sobre divisão é focado em problemas cuja solução é a obtenção do quociente. Portanto, podemos dizer que o estudo de congruência na educação básica complementa o estudo da divisão.

\subsubsection{Definição (Congruência módulo $m$ )}

Sejam $a, b$ e $m \in \mathbb{Z}$ com $m>1$, dizemos que o número a é congruente $a b$ módulo $m$, se $m$ divide a diferença entre $a$ e $b$, ou seja, $m /(a-b)$.

A notação $a \equiv b \bmod m$ representa que " $a$ é congruente a $b$ módulo $m$ " ou seja, $a \equiv b \bmod m \rightarrow m /(a-b) \leftrightarrow(a-b)=m t$, para $t \in \mathbb{Z}$.

Com a nossa definição, $a \equiv b \bmod m$ se e somente se $m /(a-b)$, ou equivalentemente, se existe um inteiro $q$ tal que $a=b+m q$.

\section{Exemplo:}

$22 \equiv 14(\bmod 2)$, pois $2 \mid 22-14$

\subsection{Aplicação da definição de congruência.}

\section{Exemplo:}

Verificaremos por meio de exemplo que dois números são congruentes modulo $m$, usando a divisão euclidiana para justificar.

Vamos verificar se 45 e 37 são congruentes na divisão por 2 .

Como $45=22.2+1$ e $37=2.18+1$, ou seja, 45 e 37 deixam o mesmo resto na divisão Euclidiana por 2. Logo $45 \equiv 37 \bmod 2$.

\subsubsection{Proposição (Caracterização das congruências módulo $m$ )}

Dois números inteiros $a$ e $b$ são congruentes módulo $m$, se e somente se, $a$ e $b$ deixam o mesmo resto quando divididos por $m$. 


\section{Demonstração:}

Supondo que $a \equiv b \bmod m$, resulta pela definição de congruência, que: $m /(a-b)$, ou seja, $a-b=m t$ com $(t \in \mathbb{Z})$.

Pelo algoritmo da divisão, se $r$ é o resto da divisão de $a$ por $m$ então: $a=m q+r$ com $(0 \leq r<m)$.

Substituindo $a$ na equação anterior, teremos:

$(m q+r)-b=m t$, ou ainda, $b=m q-m t+r=m(q-t)+r$.

Portanto, $a$ e $b$ tem o mesmo resto quando divididos por $m$.

Reciprocamente, seja $r$ o resto da divisão de $a$ e $b$ por $m$. Logo:

$a=m k+r, \operatorname{com} k \in \mathbb{Z}$.

e

$b=m t+r, \operatorname{com} t \in \mathbb{Z}$.

Subtraindo $b$ de $a$, obteremos $a-b=(k-t) m$. Portanto, pela definição que temos de congruência segue que $a \equiv b \bmod m$.

A proposição acima evidência a relação entre congruência e o resto da divisão. Notemos que todo número inteiro é congruente módulo $m$ ao resto de sua divisão por $m$. De fato: $(D=d m+r \operatorname{com} 0 \leq r<m) \leftrightarrow(D \equiv r \bmod m)$.

\subsubsection{Proposição}

A congruência módulo $m$ é reflexiva, simétrica e transitiva:

a) (Reflexiva). Com efeito, $a-a=0$ e como $m / 0$ daí conclui-se que $a \equiv a \bmod m$.

b) (Simétrica). Se $a \equiv b \bmod m$, então temos $a-b=t m$ com $(t \in \mathbb{Z})$. Como: $b-a=-(t m)=(-t) m$, segue que $b=a \bmod m$.

c) (Transitiva). Se $a \equiv b \bmod m$ e $b \equiv c \bmod m, \operatorname{logo}$ :

$a-b=t m$ e $b-c=k m$ com $(t, k \in \mathbb{Z})$.

Portanto: $a-c=(a-b)+(b-c)=t m+k m=(k+t) m$, ou seja, $a \equiv c \bmod m$. 


\subsection{Propriedades operatórias das congruências.}

A proposição abaixo mostra que: adição, subtração e multiplicação dos inteiros preservam a congruência módulo $m$.

\section{Exemplo:}

Vejamos por meio de exemplos que na congruência módulo $m$, é válida a proposição enunciada e demonstrada abaixo:

Na divisão por 7 , temos $11 \equiv 4 \bmod 7$ e $19 \equiv 5 \bmod 7$, então:

a) $11+19 \equiv 4+5 \bmod 7 \rightarrow 30 \equiv 9 \bmod 7$

b) $11.19 \equiv 4.5 \bmod 7 \rightarrow 209 \equiv 20 \bmod 7$

\subsubsection{Proposição}

Sejam $a, b, c, d, m \in \mathbb{Z}$, com $m>1$. São válidas as seguintes propriedades:

a) Se $a \equiv b \bmod m$, então, $a \pm c \equiv b \pm c \bmod m$ e $a c \equiv b c \bmod m$.

b) Se $a \equiv b \bmod m$ e $\quad c \equiv d \bmod m$, então $a \pm c \equiv b \pm d \bmod m$ e $a c \equiv b d \bmod m$.

\section{Demonstração:}

a) Pela definição de congruência, $a \equiv b \bmod m \operatorname{logo} a-b=t m$ para $t$ inteiro. Como $a-b=(a \pm c)-(b \pm c)$, segue que $(a \pm c) \equiv(b \pm c) \bmod m$.

Para multiplicação, $a \equiv b \bmod m$, temos, que $a-b=t m$ para $t$ inteiro. Logo $a c-b c=c t m$ o que implica em $m /(a c-b c)$. Portanto $a c \equiv b c \bmod m$.

b) Como $a \equiv b \bmod m, c \equiv d \bmod m$, segue $a-b=t m$ e $c-d=k m$.

Somando e subtraindo as expressões membro a membro obteremos $(a+c)-(b+d)=(t+k) m$ e $(a-c)-(b-d)=(t-k) m$.

Portanto $a \pm c \equiv b \pm d \bmod m$.

Para segunda parte, multiplicamos as expressões $a-b=t m$ e $c-d=k m$ respectivamente por $c$ e $b$, em seguida somamos membro a membro obteremos $(a-b) c+(c-d) b=c t m+b k m$, o que implica em $a c-b d=(c t+b k) m$.

Portanto: $a c \equiv b d \bmod m$. 


\subsubsection{Corolário}

Dados $a, b, m \in \mathbb{Z}$ com $(m>1)$, se $a \equiv b \bmod m$ com $a, b \in \mathbb{Z}$ e $n \in \mathbb{I N}^{*}$, então $a^{n} \equiv b^{n} \bmod m$.

\section{Demonstração:}

Usaremos Indução sobre $n$. Para $n=1$ o resultado é óbvio.

Suponhamos que o resultado seja válido para $k>1$, onde $k$ é um inteiro, ou seja, $a^{k} \equiv b^{k} \bmod m$.

Usando o item (b) da proposição 4.3.1., obtemos $\left(a^{k}\right) a \equiv\left(b^{k}\right) b \bmod m$, ou seja, $a^{k+1} \equiv b^{k+1} \bmod m$. Portanto $a^{n} \equiv b^{n} \bmod m$ para $a, b, n, m \in \mathbb{Z}$.

\subsubsection{Proposição}

Se $a c \equiv b c \bmod m$ e $m d c(c, m)=d$, então $a \equiv b \bmod \frac{m}{d}$.

\section{Demonstração:}

Se $a c \equiv b c \bmod m$, então $a c-b c=(a-b) c=k m$, com $k \in \mathbb{Z}$. Se $m d c(c, m)=d$, então existem inteiros $r$ e $s$ tais que $c=d r$ e $m=d s$, onde $r$ e $s$ são primos entre si. Logo, $(a-b) d r=k d s \rightarrow(a-b) r=k s$.

Mas isso implica que $s /(b-a) r$. Como o $m d c(r, s)=1$ segue que $s /(b-a) \rightarrow a \equiv b \bmod s$ com $s=\frac{m}{d}$. Portanto $a \equiv b \bmod \frac{m}{d}$.

\subsubsection{Corolário}

Se $a c \equiv b c \bmod m$ e se $m d c(c, m)=1$, então $a \equiv b \bmod m$.

\section{Demonstração:}

Basta fazer $d=1$ na proposição 4.3.3.

Essa propriedade garante o cancelamento de fatores em ambos os membros de uma congruência se eles são primos como módulo.

\subsubsection{Proposição}

Seja $a, b, n, m \in \mathbb{Z}$, com $m, n>1$, então: 
a) Se $a \equiv b \bmod m$ e $n / m$, então $a \equiv b \bmod n$.

b) Se $a \equiv b \bmod m$, então $m d c(a, m)=m d c(b, m)$.

\section{Demonstração:}

Sem perda de generalidade, tomaremos $b \leq a$.

a) Pela definição de congruência, vale que $m /(a-b)$. Como $n / m$, resulta que $n /(a-b)$. Portanto $a \equiv b \bmod n$. Pela definição das congruências, se $a \equiv b \bmod m$, então $a-b=m k$, ou seja, $a=m k+b$ para $k \in \mathbb{Z}$. Pelo lema de Euclides obtemos

$m d c(a, m)=m d c(m k+b, m)=m d c(b, m)$

\section{Exemplo:}

Mostre que $10^{200}-1$ é divisível por 11 .

Solução:

$10 \equiv-1 \bmod 11$

$10^{200} \equiv(-1)^{200} \bmod 11$

$10^{200} \equiv 1^{200} \bmod 11$

$10^{200}-1 \equiv 0 \bmod 11$

Portanto $11 \mid 100^{200}-1$ 


\section{Capítulo 5}

\section{Números Racionais}

$\mathrm{Na}$ construção desse capítulo tomamos como referências [9] e [10]. Desde o início da criação da matemática viu-se a necessidade do surgimento dos números, pois problemas práticos exigiam o desenvolvimento de conjuntos como os racionais para dar solução a algumas situações. Sabe-se que os egípcios, babilônios e gregos dominavam operações que envolviam alguns conceitos de números racionais.

Estudamos até aqui relações binárias entre os números inteiros tais como menor e igual, divide e congruente que são relações usadas diariamente em matemática e também no dia-a-dia das pessoas. Uma relação binária de equivalência é uma relação reflexiva, simétrica e transitiva como discutiremos no decorrer desse capítulo.

\section{Exemplo:}

Os pares $(2,4),(3,6)$ e $(1,2)$ são todos números representados do mesmo racional, o que apóia a noção de relação de equivalência.

\subsection{Construção, operação e relação de ordem.}

\subsubsection{Definição}

Seja $\mathbb{Z}^{*}=\{n \in \mathbb{Z} / n \neq 0\}$ e consideremos $\mathbb{Z} x \mathbb{Z}^{*}=\left\{(m, n) / n \in \mathbb{Z}^{*}\right\}$ a relacão definida por $(m, n) \sim(p, q)$, se e somente se, $m q=n p$.

Para valem as três propriedades que caracterizam uma relação equivalente, ou seja:

1. $(m, n) \sim(m, n)$ se, para todo $(m, n) \in \mathbb{Z} \times \mathbb{Z}^{*}$ (reflexiva)

2. $\quad(m, n) \sim(p, q) \rightarrow(p, q) \sim(m, n)$ (simétrica)

3. $(m, n) \sim(p, q)$ e $(p, q) \sim(r, s) \rightarrow(m, n) \sim(r, s)$ (transitiva)

Verifiquemos 3 já que 1 e 2 decorrem diretamente da definição.

Por hipótese: $m q=n p$ e $p s=q r$. Multiplicando a primeira dessas igualdades por $s$ e a segunda por $n$, resulta $m q s=n p s$ e $n p s=n q r$. Daí, $m q s=n q r$ e, portanto, cancelando $q$, o que é possível, pois $q \in \mathbb{Z}^{\star}$, obtém-se $m s=n r$. 
Onde $(m, n) \sim(r, s)$.

Logo a relação determina sobre $\mathbb{Z x Z}^{*}$ uma partição em classes de equivalência. Para cada par $(m, n) \in \mathbb{Z x} \mathbb{Z}^{*}$, a classe de equivalência à qual esse elemento pertence será indicado por $\frac{m}{n}$. Ou seja:

$$
\frac{m}{n}=\left\{(x, y) \in \mathbb{Z} \times \mathbb{Z}^{*} /(x, y) \sim(m, n)\right\}=\left\{(x, y) \in \mathbb{Z} \times \mathbb{Z}^{*} / n x=m y\right\} .
$$

Devido à propriedade reflexiva, é claro que $(m, n) \in \frac{m}{n}$, para todo $(m, n) \in \mathbb{Z} \times \mathbb{Z}^{*}$, além disso, como

$$
\frac{m}{n}=\frac{r}{s} \leftrightarrow(m, n) \sim(r, s)
$$

(resulta da teoria das relações de equivalência), então:

$$
\frac{m}{n}=\frac{r}{s} \leftrightarrow m s=n r
$$

O conjunto quociente de $\mathbb{Z x} \mathbb{Z}^{*}$ por $\sim$, ou seja, o conjunto de todas as classes de equivalência determinada por sobre $\mathbb{Z} x \mathbb{Z}^{*}$, será designado por $\mathbb{Q}$. Logo:

$$
\mathbb{Q}=\left\{\frac{m}{n} /(m, n) \in \mathbb{Z} \mathbf{X}^{*}\right\} .
$$

Assim, cada $a \in \mathbb{Q}$ admite infinitas representações $\frac{m}{n}\left(m \in \mathbb{Z} ; n \in \mathbb{Z}^{*}\right)$, essa representação é chamada fração. Em cada uma delas $m$ é o numerador e $n$ é o denominador. Duas frações que representam uma mesma classe de equivalência são chamadas de frações equivalentes.

Dois elementos $a$ e $b \in \mathbb{Q}$ sempre admitem representação de denominadores iguais. De fato, se $a=\frac{m}{n}$ e $b=\frac{r}{s}$, então:

$$
\frac{m}{n}=\frac{m s}{n s} \mathrm{e} \frac{r}{s}=\frac{n r}{n s}
$$

Pois $m(n s)=n(m s)$ e $r(n s)=s(n r)$. 
Os elementos de $\mathbb{Q}$ são chamados números racionais desde que se definam adição, multiplicação e relação de ordem, conforme o faremos nos itens seguintes.

\subsection{Adição em $\mathbb{Q}$}

\subsubsection{Definição}

Sejam $a=\frac{m}{n}$ e $b=\frac{r}{s}$ elementos de $\mathbb{Q}$, chamam-se de a mais $b$ e indica-se por $a+b$ o elemento de $\mathbb{Q}$ definido da seguinte maneira:

$a+b=\frac{m s+n r}{n s}$.

Seja $a=\frac{1}{2}$ e $b=\frac{1}{3}$, então $a+b=\frac{1}{2}+\frac{1}{3}$.

$a+b=\frac{1.5+3.2}{2.5}$, portanto $a+b=\frac{11}{10}$.

Mostremos que a soma $a+b$ independe dos pares ordenados escolhidos para definir $a$ e $b$, de fato, $a=\frac{m}{n}=\frac{m^{\prime}}{n^{\prime}}$, e $b=\frac{r}{s}=\frac{r^{\prime}}{s^{\prime}}$, então:

$m n^{\prime}=n m^{\prime}$ e $r s^{\prime}=s r^{\prime}$.

Multiplicando a primeira dessas igualdades por $s s^{\prime}$ e a segunda por $n n^{\prime}$ e somando membro a membro as relações obtidas

$m s n^{\prime} s^{\prime}+r n s^{\prime} n^{\prime}=n s m^{\prime} s^{\prime}+n s r^{\prime} n^{\prime}$

Ou seja:

$(m s+r n) n^{\prime} s^{\prime}=n s\left(m^{\prime} s^{\prime}+r^{\prime} n^{\prime}\right)$

O que garante

$$
\frac{m s+r n}{n s}=\frac{m^{\prime} s^{\prime}+r^{\prime} n^{\prime}}{n^{\prime} s^{\prime}}
$$

Portanto a correspondência $(a, b) \rightarrow a+b$, conforme a definição 5.2.1 é uma aplicação, portanto, trata-se de uma operação sobre $\mathbb{Q}$, chamada adição em $\mathbb{Q}$.

Para a adição em $\mathbb{Q}$ valem as seguintes propriedades:

1. $(a+b)+c=a+(b+c), \forall a, b, c \in \mathbb{Q}$ (associativa). 
2. $a+b=b+a, \forall a, b, c \in \mathbb{Q}$ (comutativa)

3. Elemento neutro: é a classe de equivalência $\frac{0}{1}=\frac{0}{2}=\ldots$, que indicamos por 0 apenas. De fato:

$$
\begin{aligned}
& \frac{m}{n}+\frac{0}{1}=\frac{m \cdot 1+0 . n}{n \cdot 1}=\frac{m \cdot 1}{n \cdot 1}=\frac{m}{n} \\
& \text { Para todo } \frac{m}{n} \in \mathbb{Q} .
\end{aligned}
$$

4. Todo $a \in \mathbb{Q}$ admite simétrico aditivo (oposto) em $\mathbb{Q}$, se $a=\frac{m}{n}$, então $-a=\frac{-m}{n}$, pois:

$$
\frac{m}{n}+\frac{-m}{n}=\frac{m+(-m)}{m}=\frac{0}{m}=0
$$

Usaremos a notação $\mathbb{Q}^{*}=\{a \in \mathbb{Q} / a \neq 0\}$.

\subsubsection{Definição}

Se $a, b \in \mathbb{Q}$, denomina-se diferença entre $a$ e $b$ indica-se por $a-b$ o seguinte elemento em $\mathbb{Q}$ :

$a-b=a+(-b)$

Como $(-b) \in \mathbb{Q}$, para todo $b \in \mathbb{Q}$, então:

$(a, b) \rightarrow a-b$

É uma operação sobre $\mathbb{Q}$, à qual chamamos subtração em $\mathbb{Q}$.

Tal como ocorre em $\mathbb{Z}$, valem em $\mathbb{Q}$ as seguintes propriedades, envolvendo a idéia de oposto e de subtração:

$$
\begin{aligned}
& -(-a+b)=a-b \\
& (a-b)+b=a \\
& a+x=b \rightarrow x=b-a \\
& a+b=a+c \rightarrow b=c
\end{aligned}
$$




\subsection{Multiplicação em $\mathbb{Q}$.}

\subsubsection{Definição}

Chamamos produto de $a=\frac{m}{n} \in \mathbb{Q}$ por $b=\frac{r}{s} \in \mathbb{Q}$ o elemento $a b=\frac{m r}{n s} \in \mathbb{Q}$

A multiplicação em $\mathbb{Q}$ é a operação definida por $(a, b) \rightarrow a b$ para quaisquer $a$ e $b \in \mathbb{Q}$.

\section{Exemplo:}

Seja $a=\frac{1}{2}$ e $b=\frac{3}{5}$, então $a \cdot b=\frac{1}{2} \cdot \frac{3}{5}$

$a \cdot b=\frac{1.3}{2.5}$, portanto $a \cdot b=\frac{3}{10}$

Valem as seguintes propriedades:

1. $a(b c)=(a b) c, \forall a, b, c \in \mathbb{Q}$ (associativa).

2. $a b=b a, \forall a, b, c \in \mathbb{Q}$ (comutativa).

3. Existe elemento neutro: é a classe $\frac{1}{1}=\frac{2}{2}=\ldots$

Que indicamos simplesmente por 1. De fato para todo $\frac{m}{n} \in \mathbb{Q}$.

$$
\frac{m}{n} \cdot \frac{1}{1}=\frac{m \cdot 1}{n \cdot 1}=\frac{m}{n}
$$

4. Todo $a \in \mathbb{Q}, a \neq 0$ admite simétrico multiplicativo (inverso) se:

$$
a=\frac{m}{n} .
$$

Então $m \neq 0$ e daí $\frac{m}{n} \in \mathbb{Q}$, portanto:

$$
\frac{m}{n} \cdot \frac{n}{m}=\frac{m \cdot n}{n \cdot m}=1
$$

Indicado por $a^{-1}$, o inverso de $a$, então: 
$a=\frac{m}{n}, a \neq 0 \rightarrow a^{-1}=\frac{n}{m}$

Disso decorre também que se $a \neq 0$

$\left(a^{-1}\right)^{-1}=\left(\frac{n}{m}\right)^{-1}=\frac{m}{n}=a$

Outro fato importante no que se refere aos inversos $a$ e $b$ são elementos não nulos:

$(a b)^{-1}=a^{-1} b^{-1}$

De fato, como

$(a b)\left(a^{-1} b^{-1}\right)=\left(a a^{-1}\right)\left(b b^{-1}\right)=1$

Então efetivamente $a^{-1} b^{-1}$ é o inverso de $a b$.

5. A multiplicação é distributiva em relação á adição:

$a(b+c)=a b+a c, \forall a, b, c \in \mathbb{Q}$.

6. Dada uma terna $a, b$ e $c$, com $a \neq 0$, se $a b=a c$, então $b=c$. (cancelativa)

\subsubsection{Definição}

A operação de $\mathbb{Q} x \mathbb{Q}^{*}$ em $\mathbb{Q}$ definida por:

$(a, b) \rightarrow a b^{-1}$

O elemento $a b^{-1}$ é chamado quociente de $a$ por $b$ e pode ser indicado por $a: b$.

\section{Exemplo:}

Seja $a=\frac{1}{2}, b=\frac{3}{5}$, então $b^{-1}=\frac{5}{3}$.

Logo $a \cdot b^{-1}=\frac{1}{2} \cdot \frac{5}{3}$, portanto $a \cdot b^{-1}=\frac{5}{6}$ 


\subsubsection{Definição (princípio da boa ordem)}

Dados dois números $\alpha$ e $\beta$, diremos que $\alpha$ é menor ou igual a $\beta$, e escrevemos $\alpha \leq \beta$ se, tomando representantes com denominadores positivos $\frac{a}{b} \mathrm{e}$ $\frac{c}{d}$ para $\alpha$ e $\beta$ respectivamente, tivermos $a d \leq b c$.

Sabemos de A.16 (princípio da boa ordem) do capítulo 3 que todo conjunto não vazio de inteiros não negativos contém um elemento mínimo, mas para o conjunto dos números racionais isso não é verdade, pois existem subconjuntos dos racionais positivos que não tem elemento mínimo.

\section{Exemplo:}

Existem no conjunto dos números racionais não-negativos que não contêm elemento mínimo. Com efeito, consideramos $M=\left\{\frac{1}{m} / m \in \mathbb{Z}\right.$ e $\left.m>0\right\}$

\section{Então:}

Vamos considerar os elementos de $M$ todos positivos, então podemos verificar que não existe mínimo para esse conjunto.

Supor por absurdo que $\frac{1}{m_{0}}$ é elemento mínimo que pertença a $M$, com $m_{0}>0$ e inteiro, mas veja que $\frac{1}{m_{0}}>\frac{1}{m_{0}+1}$, então $m_{0}+1>m_{0}$ que é uma contradição a minimalidade de $\frac{1}{m_{0}}$.

Observemos que existe outra diferença entre os conjuntos inteiro e racional. Dá proposição 3.1.7, temos que não existe inteiro entre $0 \mathrm{e} 1$, pelo exemplo citado acima, o conjunto $M$ formado por $\mathbb{Q}$ a situação é diferente.

Agora, queremos ver qual deve ser a definição geral para o principio da boa ordem em $\mathbb{Q}$. Pretendemos também que a ordem seja compatível com as operações. 


\section{Demonstração:}

Dado $\alpha=\frac{a}{b}$ com denominadores positivos devemos ter $\frac{b}{1} \geq 0$.

Se $\alpha \geq 0$, teremos $\alpha \cdot \frac{b}{1} \geq 0$, isto é $\frac{a}{b} \cdot \frac{b}{1} \geq 0$, ou seja, $\frac{a}{1} \geq 0$; logo, deve-se $a \geq 0$.

Assim, a definição razoável seria que um racional $\alpha=\frac{a}{b}$ com denominador positivo é maior ou igual a zero se e somente se o numerador a também for.

$$
\alpha=\frac{a}{b} \text { e } \beta=\frac{c}{d}
$$

Com denominadores positivos, diremos que $\alpha \leq \beta$ se $0 \leq \beta-\alpha$, isto é, $0 \leq \frac{c}{d}-\frac{a}{b}$

Donde $0 \leq \frac{b c-a d}{b d}$.

Como o denominador é positivo, a última desigualdade vale se e somente se $0 \leq b c-a d$ ou, equivalente, se $a d \leq c b$. Chegamos assim a nossa definição original: $\alpha \leq \beta$ se somente se $a d \leq b c$. 


\section{Capítulo 6}

\section{Atividades e Laboratórios}

Nesse capítulo apresentaremos atividades sugestivas para o trabalho do professor no exercício de sua docência.

Selecionamos algumas atividades referentes às operações básicas de multiplicação, divisão e frações, pois percebe-se que esses conhecimentos não estão consolidados na maioria dos alunos. Sugerimos que a aplicação e o desenvolvimento sejam feitos em duas aulas, onde primeiramente o professor promoverá uma apresentação teórica seguida da aplicação.

Esperamos que ao fim tenhamos contribuído na formação do aluno e enriquecido a diversidade de abordagens necessária para os fins docentes.

\subsection{Divisão e fração.}

\subsubsection{Frações equivalentes ao inteiro}

Objetivo: Esperamos que os alunos percebam que o inteiro pode ser dividido em partes e que essas partes são denominadas frações equivalentes, também esperamos que através da observação e do contato com a atividade o aluno aprenda a adição de frações de mesmos denominadores.

Essa atividade [12] é direcionada as séries iniciais do ensino fundamental.

Competência e habilidade: compreender o significado das frações na representação de medidas não inteira e da equivalência de frações.

Tomando cartões quadrados de mesmas dimensões, vamos mostrar que podemos criar diferentes frações.

Com um dos cartões, sem dividi-los em partes mostraremos a parte inteira que é a base para as comparações.

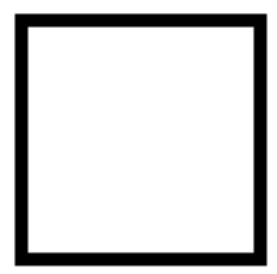

Temos o inteiro: 1

Agora tomamos outro cartão de mesma dimensão e dividido ao meio. 


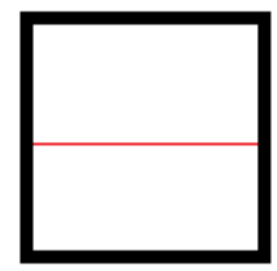

Temos assim duas metades: $\frac{1}{2}+\frac{1}{2}=1$

Agora tomamos outro cartão de mesma dimensão e dividido em quatro partes.

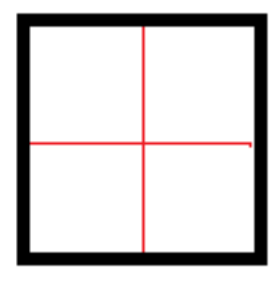

Temos assim quatro quartos: $\frac{1}{4}+\frac{1}{4}+\frac{1}{4}+\frac{1}{4}=1$

Agora tomamos outro cartão de mesma dimensão e dividido em dezesseis partes.

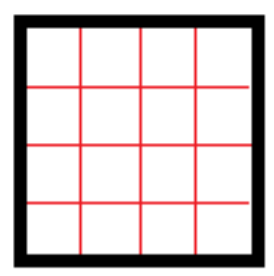

Temos assim dezesseis oitavos:

$$
\frac{1}{16}+\frac{1}{16}+\frac{1}{16}+\frac{1}{16}+\frac{1}{16}+\frac{1}{16}+\frac{1}{16}+\frac{1}{16}+\frac{1}{16}+\frac{1}{16}+\frac{1}{16}+\frac{1}{16}+\frac{1}{16}+\frac{1}{16}+\frac{1}{16}+\frac{1}{16}=1
$$

Note que nos exemplos, não só escrevemos as frações como comparamos suas equivalências.

\subsubsection{Frações de diferentes denominadores equivalentes}

Objetivo: Perceber e admitir que frações com diferentes denominadores são equivalentes por comparação entre os cartões.

Essa atividade [12] é direcionada as séries iniciais do ensino fundamental. 
Competência e habilidade: Saber realizar a operação de adição de frações e compreender o significado de suas equivalências.

Com dois cartões retangulares, vamos criar e escrever frações, os dividindo em 3 e 6 partes iguais para também determinarmos as frações equivalentes.

Vamos inicialmente dividir o primeiro cartão em três partes e representar a soma das frações.

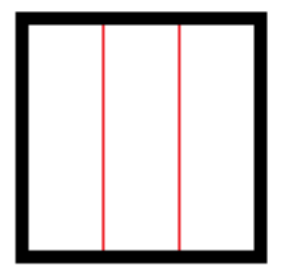

Temos três terços: $\frac{1}{3}+\frac{1}{3}+\frac{1}{3}=1$ inteiro.

Com o outro cartão, a divisão será feita em 6 partes idênticas.

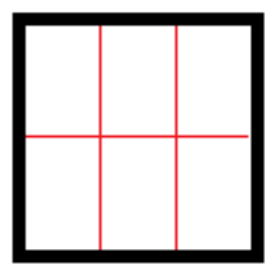

Temos seis sextos: $\frac{1}{6}+\frac{1}{6}+\frac{1}{6}+\frac{1}{6}+\frac{1}{6}+\frac{1}{6}=1$ inteiro.

Notemos que do segundo cartão temos que duas partes ou dois sextos são equivalentes a uma parte do primeiro cartão (um terço) do primeiro cartão. Escrevemos: $\frac{2}{6} \cong \frac{1}{3}$

Também temos que quatro partes do segundo cartão ou quatro sextos são equivalentes a duas partes do primeiro cartão (dois terços), então escrevemos:

$$
\frac{4}{6} \cong \frac{2}{3}
$$

Note que com esses dois cartões podemos analisar outras frações equivalentes que enriquece os conhecimentos do aluno, dando a ele a oportunidade de novas discussões para que possa entender e aprender frações equivalentes. 


\subsubsection{Frações impróprias}

Objetivo: Esperamos que os alunos compreendam o significado das frações impróprias e saibam realizar de modo significativo a operação da adição.

Competência e habilidade: compreender a idéia de números racionais em sua relação com as frações.

Essa atividade [12] é direcionada as séries iniciais do ensino fundamental.

Veja que as duas atividades anteriores mostraram como escrever o inteiro somando as parcelas, do mesmo modo mostraremos a idéia da fração imprópria.

Vamos dividir dois cartões retangulares em quatro partes iguais cada um, assim teremos:

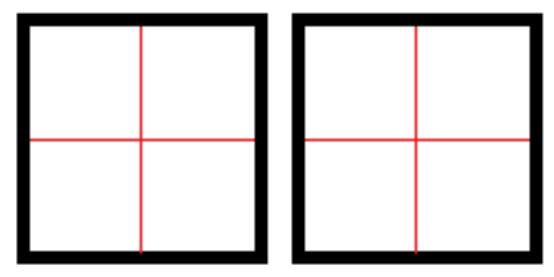

Oito quartos.

$\frac{1}{4}+\frac{1}{4}+\frac{1}{4}+\frac{1}{4}+\frac{1}{4}+\frac{1}{4}+\frac{1}{4}+\frac{1}{4}=2$ inteiros

Se tomarmos desses oito quartos apenas cinco quartos, teremos:

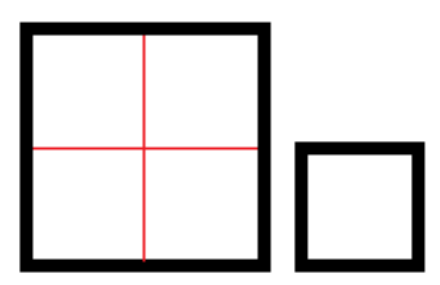

Cinco quartos ou um inteiro e um quarto.

$\frac{1}{4}+\frac{1}{4}+\frac{1}{4}+\frac{1}{4}+\frac{1}{4}=\frac{4}{4}+\frac{1}{4}$

$\frac{1}{4}+\frac{1}{4}+\frac{1}{4}+\frac{1}{4}+\frac{1}{4}=\frac{5}{4}$

$\frac{1}{4}+\frac{1}{4}+\frac{1}{4}+\frac{1}{4}+\frac{1}{4}=1 \frac{1}{4}$ 
Note que $1 \frac{1}{4}$ é o que chamamos de fração imprópria e fica muito óbvia a idéia de fração imprópria para o educando.

Agora com apenas seis quartos, teremos:

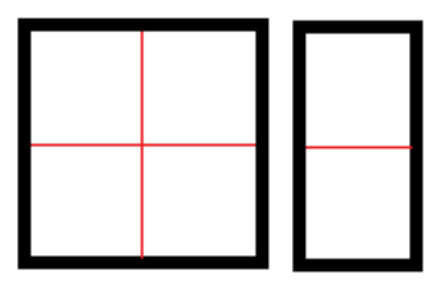

Seis quartos ou um inteiro e dois quartos.

$\frac{1}{4}+\frac{1}{4}+\frac{1}{4}+\frac{1}{4}+\frac{1}{4}+\frac{1}{4}=\frac{4}{4}+\frac{2}{4}$

$\frac{1}{4}+\frac{1}{4}+\frac{1}{4}+\frac{1}{4}+\frac{1}{4}+\frac{1}{4}=\frac{6}{4}$

$\frac{1}{4}+\frac{1}{4}+\frac{1}{4}+\frac{1}{4}+\frac{1}{4}+\frac{1}{4}=1 \frac{2}{4}$

Veja que está bem definido ao educando a idéia de fração imprópria.

As atividades citadas acima do qual se explora os conceitos de frações, tem como objetivo:

Questionar a realidade formulando-se problemas e tratando de resolvê-los, utilizando para isso o pensamento lógico, a criatividade, a intuição, a capacidade de analise crítica, selecionando procedimento e verificando sua adequação. [3]

\subsubsection{Divisão usada pelos egípcios}

Objetivo: Compreender o significado do dobro de um número e saber utilizar das diferentes formas de multiplicações de modo significativo.

Competência e habilidade: calculo da divisão através de um método alternativo.

Essa atividade [6] é direcionada as séries iniciais do ensino fundamental.

A divisão realizada pelos egípcios é análoga a multiplicação. Devemos criar duas colunas e colocar inicialmente 1 na primeira e o divisor na segunda, 
dobraremos o divisor até chegar no dividendo ou ter o máximo de aproximação sem superá-lo.

\section{Exemplo 1:}

$768: 12$

Após colocar 1 na primeira coluna, dobraremos seu valor e registraremos na próxima linha cada valor obtido. Na coluna 2, colocaremos o divisor (12), o dobraremos até chegarmos no 768.

$\begin{array}{rlrl}1 & 12 \\ 2 & 24=12.2 \\ 4=2^{2} & 48=12.2^{2} \\ 8=2^{3} & 96=12.2^{3} \\ 16=2^{4} & 192=12.2^{4} \\ 32=2^{5} & 384=12.2^{5} \\ 64=2^{6} & 768=12.2^{6}\end{array}$

Assim $768: 12=64$

Agora vamos realizar a divisão que não resulta no dividendo esperado sobre a coluna, para isso faremos adições necessárias:

Exemplo 2: $1476: 12$

Da mesma forma criaremos duas colunas e nelas colocaremos o divisor e o 1, onde dobraremos cada um deles até obtermos na coluna a máxima aproximação sem superá-lo.

$\begin{array}{rlrl}1 & 12 \\ 2 & 24=12.2 \\ 4=2^{2} & 48=12.2^{2} \\ 8=2^{3} & 96=12.2^{3} \\ 16=2^{4} & 192=12.2^{4} \\ 32=2^{5} & 384=12.2^{5} \\ 64=2^{6} & 768=12.2^{6}\end{array}$


Note que 768 é a máxima aproximação de 1476 sem superá-lo, dessa forma faremos adições a 768 para obtermos 1476.

$1476=768+384+192+96+24+12$.

Assim, teremos:

$1476: 12=(768+384+192+96+24+12): 12$

Dividindo cada termo de $(768+384+192+96+24+12)$ por 12 , temos que:

$1476: 12=64+32+16+8+2+1$

$1476: 12=123$

\subsubsection{Trabalhando com o número 1}

Objetivo: Esperamos que os alunos se apropriem do significado de frações e de representação de número muito grande ou muito pequeno.

Competência e habilidade: Cálculo mental envolvendo os conceitos de fração.

Essa atividade [4] é direcionada as séries iniciais do ensino fundamental.

Segundo os PCNs.

Embora as representações fracionarias e decimais dos números racionais sejam conteúdos desenvolvidos nos ciclos iniciais, o que se constata é que os alunos chegam ao terceiro ciclo sem compreender os diferentes significados associado a esse tipo de número e tampouco os procedimentos de cálculos. [3]

Por esse motivo a necessidade do desenvolvimento de atividade que explorem os conceitos de frações e decimais de forma diferente e investigativa para que o aluno possa brincar com os números e explorá-los.

Note que com o número 1 é possível escrevermos qualquer número natural utilizando a soma.

1

$1+1=2$

$1+1+1=3$

$1+1+1+1=4$

$1+1+1+1+1=5$ 
Mas isso também se aplica para construção de números tão pequenos quanto se queira, ou seja, para construção de frações que resultam em valores considerados pequenos.

$$
\begin{aligned}
& \frac{1}{1}=1 \\
& \frac{1}{1+1}=\frac{1}{2}=0,50 \\
& \frac{1}{1+1+1}=\frac{1}{3}=0,33 \ldots \\
& \frac{1}{1+1+1+1}=\frac{1}{4}=0,25 \\
& \frac{1}{1+1+1+1+1}=\frac{1}{5}=0,20
\end{aligned}
$$

Quando operamos com produto de números formado apenas por 1, temos:

$1.1=1$

$11.11=121$

$111.111=12321$

$1111.1111=1234321$

$11111.11111=123454321$

Esses produtos nos rendem os números poliondros que possuem propriedades curiosas. Podem ser lidos da direita para esquerda, ou da esquerda para direita que seus valores não se alteram.

Além disso, esses produtos sempre resultam em números que são escritos na seqüência dos nossos algarismos.

\subsubsection{O calendário e a divisão}

Objetivo: Saber resolver problemas práticos e conhecer o significado em diferentes contextos das operações.

Competência e habilidade: Cálculo envolvendo as técnicas de divisão. 
Essa atividade [17] é direcionada as séries iniciais do ensino fundamental, mas podendo ser adaptado e estendido ao ensino médio.

Exploraremos o conceito de divisibilidade e também o de produto fazendo com que durante a resolução e as discussões fique claro que:

É importante destacar que as situações de aprendizagem precisam estar centradas na construção de significados, na elaboração de estratégias e na resolução de problemas, em que o aluno desenvolve processos importantes como intuição, analogia, indução e dedução, e não atividade voltada para a memorização desprovida de compreensão ou de um trabalho que privilegie uma formalização precoce dos conceitos. [3]

O calendário por muito tempo teve a importância de principalmente indicar as estações do ano.

Quando o calendário estava fora de sincronia com as estações do ano, o rei Julio Cezar e seus astrônomos introduziram um dia no calendário que foi distribuído no intervalo de quatro anos, ficando assim mais tarde distribuído em 3 anos de 365 dias e um quarto ano de 366 dias, tudo distribuído em 12 meses, onde 6 meses são de 31 dias, 5 meses são de 30 dias e 1 mês é de 28 dias ou de 29 dias (quando o ano é bissexto) e semanas de 7 dias. [17]

O primeiro dia da semana do ano 1 aconteceu em uma segunda feira, então o dia 0 foi no domingo, assim para determinarmos o dia da semana após uma determinada quantidade de dias, devemos dividir por 7 .

Se o resto for 0 , esse dia é domingo.

Se o resto for 1, esse dia é segunda-feira.

Se o resto for 2, esse dia é terça-feira.

Se o resto for 3 , esse dia é quarta-feira.

Se o resto for 4, esse dia é quinta-feira.

Se o resto for 5 , esse dia é sexta-feira.

Se o resto for 6 , esse dia é sábado.

Assim, chamamos $n$ o número de dias passado desde o dia 1, do ano 1 e dividimos por 7 para determinarmos $a_{n}$ que é o dia da semana. 
$a_{n}=\frac{n}{7}$

Exemplo:

Sabendo que o dia 1 do mês 1 do ano de 2014 caiu em uma quarta- feira , vamos determinar em qual dia da semana acontecerá a data 31/12/2014.

Inicialmente vamos usar as informações citadas no início da atividade.

1 ano tem 365 dias, quando não bissexto.

1 ano tem 366 dias, quando bissexto.

Os anos bissextos são múltiplos de 4 mas não múltiplos de 100, portanto 2014 não é bissexto.

Como o ano é dividido em semana de 7 dias e de 01/01/2014 a 31/12/2014 há 365 dias, e o dia 1 aconteceu em uma quarta feira e 365/7 são 52 semanas e um dia, portanto o último dia do ano também acontecerá em uma quarta feira.

Outros problemas adaptado sobre calendário. Disponível em [11].

1. O ano de 2013 começou em uma terça feira. Em que dia da semana cairá o último dia desse ano?

2. O ano de 2013 começou em uma terça feira. Em que dia da semana cairá o ultimo dia do ano de 2016 ?

3. O ano de 2013 começou em uma terça feira. Em que dia da semana cairá o primeiro dia do ano de 2016 ?

4. Quantos calendários anuais diferentes existem?

5. Em um determinado ano o mês de abril, que possui um total de 30 dias, teve mais domingo do que sábado. Nesse ano, o feriado de primeiro de maio ocorreu em qual dia da semana?

\subsubsection{Problema. Razão}

Objetivo: Esperamos que os alunos reconheçam e saibam utilizar os conceitos de razão em diversas situações.

Competência e habilidade: Cálculo e compreensão da idéia de números racionais e sua relação com as frações e as razões. 
Essa atividade [1] é direcionada as séries iniciais do ensino fundamental, mas também podendo ser discutido no ensino médio no intuito de uma breve revisão.

Esse problema aborda os conceitos de razão, envolvendo diretamente frações equivalentes e a divisão.

Segundo os PCNs:

A resolução de problemas, na perspectiva indicada pelos educadores matemáticos, possibilita aos alunos mobilizar conhecimentos e desenvolver a capacidade de gerenciar as informações que estão ao seu alcance. Assim, os alunos terão oportunidade de ampliar seus conhecimentos a cerca dos conceitos e procedimentos matemáticos bem como ampliar a visão que tem dos problemas, da matemática, do mundo em geral e desenvolver sua autoconfiança. [3]

Dois garotos partem a uma pescaria onde pescaram $4 \mathrm{~kg} \mathrm{e} 3,2 \mathrm{~kg}$, ao fim da pescaria pagam para uma senhora limpar os peixes. Após limpos, essa senhora junta os peixes totalizando $5,76 \mathrm{~kg}$ daí surge o impasse, qual a parte de peixes que cabe a cada garoto?

Escrevendo a razão entre a quantia de peixes pescado pelos garotos, temos:

$\frac{3,2 \mathrm{~kg}}{4,0 \mathrm{~kg}}$

Multiplicando os numerador e o denominador por 10, temos:

$\frac{3,2.10}{4,0.10}=\frac{32}{40}$

Dividindo o numerador e o denominador por 8, temos:

$\frac{32: 8}{40: 8}=\frac{4}{5}$

Que é uma fração irredutível, agora vamos entender essa fração. Dividindo o número total de peixes por 9 partes, teremos 4 partes para o garoto que menos pescou e 5 partes para o garoto que mais pescou.

$$
5,76 \lcm{\frac{9}{0,64}}
$$

Portanto: 
4 . 0,64 $=2,56 \mathrm{~kg}$ é a parte que cabe ao garoto que menos pescou.

$5 \cdot 0,64=3,20 \mathrm{~kg}$ é a parte que cabe ao garoto que mais pescou.

\subsubsection{Divisão por 9. (truque)}

Objetivo: Conhecer, compreender e aplicar alguns procedimentos para resolução de operações.

Competência e habilidade: Cálculo envolvendo a operação da divisão.

Essa atividade [8] é direcionada as séries iniciais do ensino fundamental.

A atividade tem como foco discutir um meio rápido e prático de dividir qualquer número inteiro por 9 .

Segundo os PCNs:

O exercício da indução e da dedução em matemática reveste-se da importância no desenvolvimento da capacidade de resolver problemas, de formular e testar hipóteses, de deduzir, de generalizar e de inferir dentro da determinada lógica, o que assegura um papel de relevo ao aprendizado dessa ciência em todos os níveis de ensino. [3]

Para realizarmos as divisões (23:9), (1271:9) e (421:9), devemos proceder do seguinte modo:

\section{Exemplo 1:}

Inicialmente colocamos (23:9) em uma tabela como segue:

\begin{tabular}{|l|l|l|}
\hline 2 & 3 & 9 \\
\hline & & \\
\hline & & \\
\hline
\end{tabular}

O primeiro algarismo do dividendo deve descer para linha de baixo (no caso o número 2), esse algarismo deve ser adicionado ao próximo algarismo do dividendo (no caso o número 3 ) e o resultado colocado debaixo do algarismo 3.

\begin{tabular}{|l|l|l|}
\hline 2 & 3 & 9 \\
\hline 2 & 5 & \\
\hline & & \\
\hline
\end{tabular}


Por fim, temos que o último algarismo acrescentado na nossa tabela é o resto da divisão de 23 por 9 (no caso o número 5 é o resto) e o restante (no caso o número 2) é o quociente da divisão, portanto:

$23: 9=2.9+5$

Exemplo 2:

Agora vamos dividir 421 por 9 do mesmo modo.

\begin{tabular}{|l|l|l|l|}
\hline 4 & 2 & 1 & 9 \\
\hline & & & \\
\hline & & & \\
\hline
\end{tabular}

Inicialmente o primeiro algarismo do dividendo deve ocupar a linha abaixo dele (no caso o algarismo 4), esse algarismo é adicionado ao próximo algarismo do dividendo (no caso o algarismo 2) e o resultado colocado abaixo do algarismo 2 (no caso o algarismo 6). Agora adicionamos esse resultado ao próximo algarismo do dividendo (no caso o algarismo 1) e o resultado colocado abaixo do algarismo 1 (no caso $o$ algarismo 7 ).

\begin{tabular}{|l|l|l|l|}
\hline 4 & 2 & 1 & 9 \\
\hline 4 & 6 & 7 & \\
\hline & & & \\
\hline
\end{tabular}

Note que 7 é o resto da divisão de 421 por 9 e 46 é o quociente dos mesmos, portanto:

$421: 9=46.9+7$

Exemplo 3

Na divisão de 1271 por 9 , temos:

\begin{tabular}{|l|l|l|l|l|}
\hline 1 & 2 & 7 & 1 & 9 \\
\hline & & & & \\
\hline & & & & \\
\hline
\end{tabular}

Vamos inicialmente colocar o primeiro algarismo do dividendo na linha debaixo de nossa tabela e operar como nos itens anteriores, mas note que após 
adicionarmos o algarismo 1 ao algarismo 2, teremos como próxima adição dos algarismos 3 ao 7 que resulta em 10, onde se faz necessário o uso da nossa terceira linha da tabela, colocaremos o algarismo 1 na terceira linha e o 0 na segunda linha abaixo do algarismo 7 , assim continuamos o processo adicionando 0 algarismo 0 ao 1 e colocando o resultado na segunda linha abaixo do algarismo 1 .

\begin{tabular}{|l|c|c|c|c|}
\hline 1 & 2 & 7 & 1 & 9 \\
\hline 1 & 3 & 0 & 1 & \\
\hline & 1 & & & \\
\hline
\end{tabular}

Para finalizarmos a divisão, agora na terceira linha operamos adicionando os algarismos 1 ao 0 e colocando o resultado na terceira linha abaixo do algarismo 0 , assim concluímos o processo adicionando o algarismo 1 da segunda linha ao algarismo 1 da terceira linha e colocando o resultado ( 2 ) abaixo do algarismo 1.

\begin{tabular}{|l|c|c|c|c|}
\hline 1 & 2 & 7 & 1 & 9 \\
\hline 1 & 3 & 0 & 1 & \\
\hline & 1 & 1 & 2 & \\
\hline
\end{tabular}

Por fim, adicionamos as duas últimas linhas obtidas para encontrarmos 0 quociente, onde o último algarismo da segunda linha é o resto.

\begin{tabular}{|l|c|c|c|c|}
\hline 1 & 2 & 7 & 1 & 9 \\
\hline 1 & 3 & 0 & 1 & \\
\hline & 1 & 1 & 2 & \\
\hline 1 & 4 & 1 & & \\
\hline
\end{tabular}

2 é o resto da nossa divisão de 1271 por 9 e 141 é o quociente, portanto:

$1271: 9=141.9+2$

\section{Justificativa Matemática}

Tomamos como exemplo um número qualquer formado por quatro algarismos $N=a_{3} \cdot a_{2} \cdot a_{1} \cdot a_{0}$, escrito na base 10 , podendo ser representado por: $N=a_{3} \cdot 10^{3}+a_{2} \cdot 10^{2}+a_{1} 10^{1}+a_{0}$. Fazendo: 


$$
\begin{aligned}
& \frac{N}{9}=\frac{a_{3}}{9} \cdot 10^{3}+\frac{a_{2}}{9} \cdot 10^{2}+\frac{a_{1}}{9} \cdot 10^{1}+\frac{a_{0}}{9} \\
& \frac{N}{9}=\frac{a_{3}}{9} \cdot(999+1)+\frac{a_{2}}{9} \cdot(99+1)+\frac{a_{1}}{9} \cdot(9+1)+\frac{a_{0}}{9} \\
& \frac{N}{9}=\frac{999 a_{3}}{9}+\frac{a_{3}}{9}+\frac{99 a_{2}}{9}+\frac{a_{2}}{9}+\frac{9 a_{1}}{9}+\frac{a_{1}}{9}+\frac{a_{0}}{9} \\
& \frac{N}{9}=111 a_{3}+11 a_{2}+1 a_{1}+\frac{a_{3}+a_{2}+a_{1}+a_{0}}{9} \\
& \frac{N}{9}=100 a_{3}+10\left(a_{3}+a_{2}\right)+\left(a_{3}+a_{2}+a_{1}\right)+\frac{a_{3}+a_{2}+a_{1}+a_{0}}{9}
\end{aligned}
$$

\subsubsection{Divisão por 99. (truque)}

Objetivo: Encontrar novos caminhos para cálculo da divisão.

Competência e habilidade: Conhecer, compreender e aplicar alguns procedimentos para resolução de operações.

Essa atividade [8] é direcionada as séries iniciais do ensino fundamental.

Na divisão por 99, podemos aplicar o mesmo truque visto na divisão por 9 , tomemos como exemplo as divisões de 4281 por 99 e 12967721 por 99.

Exemplo 1

Vamos determinar o quociente de 4281 por 99 através dos seguintes passos:

\begin{tabular}{|l|l|l|}
\hline 42 & 81 & 99 \\
\hline & & \\
\hline & & \\
\hline
\end{tabular}

Colocaremos o 42 na segunda linha e executaremos a adição de 42 e 81, assim teremos como solução 123 que supera as dezenas, por esse motivo usará a terceira linha para completar o processo.

\begin{tabular}{|l|c|c|}
\hline 42 & 81 & 99 \\
\hline 42 & 23 & \\
\hline 1 & & \\
\hline
\end{tabular}


Para concluirmos iremos adicionar 1 pertencente a terceira linha ao 23 pertencente a segunda linha, o resultado obtido colocaremos abaixo do 23 na terceira linha.

\begin{tabular}{|c|c|c|}
\hline 42 & 81 & 99 \\
\hline 42 & 23 & \\
\hline 1 & 24 & \\
\hline
\end{tabular}

Para determinarmos o quociente adicionamos as duas últimas linhas, onde a última dezena da segunda linha é o resto da divisão.

\begin{tabular}{|c|c|c|}
\hline 42 & 81 & 99 \\
\hline 42 & 23 & \\
\hline 1 & 24 & \\
\hline 43 & & \\
\hline
\end{tabular}

Daí tem-se que 24 é o resto da divisão de 4281 por 99 e 43 (obtido da soma de $42+1$ ) é o quociente, portanto:

$$
\begin{aligned}
& 4281: 99=43.99+24 \\
& \text { Exemplo } 2
\end{aligned}
$$

Vamos determinar o quociente de 12967721 por 99.

\begin{tabular}{|l|l|l|l|l|}
\hline 12 & 96 & 77 & 21 & 99 \\
\hline & & & & \\
\hline & & & & \\
\hline
\end{tabular}

Agora procederemos nessa divisão de mesmo modo que nas anteriores.

\begin{tabular}{|c|c|c|c|c|}
\hline 12 & 96 & 77 & 21 & 99 \\
\hline 12 & 08 & 85 & 06 & \\
\hline 1 & 1 & 2 & & \\
\hline
\end{tabular}

Para finalizarmos, calculamos cada termo da terceira linha para enfim efetuarmos a adição entre a segunda e terceira linha. 


\begin{tabular}{|c|c|c|c|c|}
\hline 12 & 96 & 77 & 21 & 99 \\
\hline 12 & 08 & 85 & 06 & \\
\hline 1 & 1 & 2 & 08 & \\
\hline
\end{tabular}

Assim, teremos:

\begin{tabular}{|c|c|c|c|c|}
\hline 12 & 96 & 77 & 21 & 99 \\
\hline 12 & 08 & 85 & 06 & \\
\hline 1 & 1 & 2 & 08 & \\
\hline 13 & 09 & 87 & & \\
\hline
\end{tabular}

Portanto a divisão de 12967721 por 99, nós dá resto 08 e quociente 130987, logo:

$12967721=130987.99+08$

\subsubsection{Frações e divisões como partilha}

Objetivo: Compreender situações problema que envolva proporcionalidade, sabendo representá-la por meio de equação.

Competência e habilidade: Cálculo e técnicas de resolução de equações para resolução de situação-problema.

Essa atividade [16] é direcionada as séries iniciais do ensino médio.

Esse problema envolve conceitos fundamentais de divisão, equação, razão e um nível alto de interpretação.

De acordo com os PCNs:

O ensino de matemática deve garantir o desenvolvimento de capacidade como: observação, estabelecimento de relações, comunicação (diferentes linguagens), argumentação e validação de processos e o estímulo as formas de raciocínio como intuição, indução, dedução, analogia, estimativa. [3]

Um Rajá deixou as suas filhas certo número de pérolas e determinou que a divisão se fizesse do seguinte modo:

- A filha mais velha tiraria uma pérola e um sétimo do que restasse. 
- Viria, depois a segunda filha e tomaria para si 2 pérolas e um sétimo do que restasse.

- A seguir, a terceira jovem receberia 3 pérolas e um sétimo do que restasse.

E assim sucessivamente.

As filhas mais moças apresentaram queixa a um juiz, alegando que por esse sistema complicado de partilhas, elas seriam fatalmente prejudicadas.

O juiz que - reza a tradição - era hábil nas resoluções de problemas, respondeu prontamente que as reclamantes estavam enganadas e que a divisão proposta pelo velho Rajá era justa e perfeita e tinha razão. Feito a partilha, cada um de seus herdeiros recebeu o mesmo número de pérolas.

Pergunta-se:

Qual o número de pérolas?

Quantas são as filhas de Rajá?

Solução:

x o número de pérolas do Rajá.

Sejam as filhas de Rajá representadas por $F_{1}, F_{2}, F_{3}, \ldots$ da mais velha para a mais nova.

Segundo enunciado do problema, a filha mais velha $F_{1}$ retirou uma pérola e $\frac{1}{7}$ do que restasse. Então, como existiam $x$ pérolas, ao retirar uma, ficariam $(x-1)$ pérolas.

Desse restante pela regra estabelecida pelo Rajá, ela retirou $\frac{1}{7}$, ou seja, $\frac{1}{7}(x-1)$. Chamamos de $n\left(F_{1}\right)=1+\frac{1}{7}(x-1)$ o número de pérolas que a filha mais velha $F_{1}$ ficou.

$$
n\left(F_{1}\right)=1+\frac{1}{7}(x-1)=\frac{6-x}{7}
$$

Ou seja, restam: 
$x-n\left(F_{1}\right)=x-\frac{x+6}{7}=\frac{6 x-6}{7}$ pérolas.

Agora a filha $F_{2}$ vem e retira duas pérolas, conforme o enunciado. Resta então a seguinte quantidade de pérolas.

$\frac{(6 x-6)}{7}-2=\frac{6 x-20}{7}$

Deste ele retirou $\frac{1}{7}$, ou seja:

$\frac{1}{7} \cdot \frac{(6 x-20)}{7}=\frac{6 x-20}{49}$

Portanto o número de pérolas da filha $F_{2}$ será igual à:

$n\left(F_{2}\right)=2+\frac{(6 x-20)}{49}=\frac{78+6 x}{49}$ pérolas.

Poderíamos agora achar a expressão que defini o número de pérolas da terceira filha $F_{3}$, mas não é necessário, pois o problema diz que a divisão proposta por Rajá era justa e perfeita, o que significa que todas as filhas receberão quantidades iguais de pérolas. Portanto:

$$
\begin{aligned}
& n\left(F_{1}\right)=n\left(F_{2}\right)=n\left(F_{3}\right) \\
& \frac{x+6}{7}=\frac{6 x+78}{49}
\end{aligned}
$$

Efetuando, temos:

$7 x+42=6 x+78$

$1 x=36$

Portanto são 36 pérolas para a divisão entre as filha.

Vejamos então a distribuição das pérolas conforme os dados do problema.

A filha mais velha $F_{1}$, retira 1 pérola $(36-1=35$ pérolas $)$ e dessas retira $\frac{1}{7}$. Como, $\left(\frac{1}{7}\right.$ de $\left.35=5\right)$ logo a filha 1 retirou 6 pérolas. 
Como dito que todas as filhas recebem o mesmo número de pérolas, já que a divisão proposta por Rajá era dita justa é perfeita, como restava $36-6=30$ pérolas, é claro que as 30 pérolas foram distribuídas $\frac{30}{6}=5$ filhas.

Portanto Rajá possui 6 filhas.

\subsection{Multiplicação}

\subsubsection{Cálculos digitais}

Objetivo: Saber calcular diferentes situações problema recorrendo a raciocínios, sem a necessidade de aplicações de fórmulas ou memorização.

Competência e habilidade: Cálculo mental envolvendo técnicas da multiplicação.

Essa atividade [6] é direcionada as séries iniciais do ensino fundamental, mas podendo ser estendido ao ensino médio.

Este procedimento é antigo e foi descoberto de modo empírico, permitindo efetuar multiplicação de números compreendidos entre 5 e 10. Essa atividade ajudará o aluno em seu desempenho com as devidas multiplicações dos quais se referem esse texto.

\section{Exemplo:}

Para multiplicar 7 por 8, dobramos na mão direita os dedos correspondente as unidades suplementares de 7 em relação a 5 (isto é $7-5=2$ dedos) dobrando na outra mão os dedos equivalentes as unidades suplementar de 8 em relação a 5 (isto é $8-5=3$ ). Os resultados obtidos das subtrações serão somados e multiplicados por $10,(2+3) .10=50$ e acrescentando a esse resultado parcial o produto dos dedos levantados de uma de suas mãos pelos dedos da outra mão, isto é $(2$. $3=6)$.

Então teremos:

$7 \cdot 8=(2+3) \cdot 10+(2 \cdot 3)=56$

\section{Justificativa matemática}

Sejam a e b dois números compreendidos entre 5 e 10, o produto entre eles será dado por $a$. $b$, onde a e b são iguais ou maiores que 5 então:

(a - 5) são os dedos dobrados na mão direita. 
$(b-5)$ são os dedos dobrados na mão esquerda.

Isso é equivalente no exemplo anterior a:

$(7-5)=2$ dedos dobrados na mão direita.

$(8-5)=3$ dedos dobrados na mão esquerda.

Os dedos dobrados nas mãos devem ser somados e depois multiplicados por 10 , assim teremos dezenas referentes ao resultado.

$[(a-5)+(b-5)] \cdot 10$, veja no exemplo isso é equivalente à $(2+3) \cdot 10=50$.

Agora os dedos não dobados devem ser multiplicados entre si.

5 - (a - 5) são os dedos não dobrados na mão direita.

5 - (b - 5) são os dedos não dobrados na mão esquerda .

Logo temos:

[5 - (5 - a)].[5 - (5 - b)] que refere-se a parte das unidades que será adicionada ao resultado anterior.

Por exemplo: 3 dedos não dobrados na mão direita e 2 dedos não dobrados na mão esquerda, o produto entre eles será $3.2=6$.

Por fim basta adicionarmos os resultados.

$[(a-5)+(b-5)]+[5-(5-a)] \cdot[5-(5-b)]$

Que é o mesmo que fazermos $50+6=56$.

\subsubsection{Multiplicação usada pelos egípcios}

Objetivo: Compreender o significado do dobro de um número e saber utilizar das diferentes formas de multiplicações de modo significativo.

Competência e habilidade: Cálculo da multiplicação envolvendo método alternativo.

Essa atividade [6] é direcionada as séries iniciais do ensino fundamental.

Os conhecimentos abrangidos são os da divisão e o da multiplicação, dirigidos ao ensino fundamental na perspectiva de dar aos educando uma nova visão da divisão e da multiplicação de números inteiros possibilitando aos mesmos 
mais uma ferramenta de trabalho, ou seja, mais um modo de discutir problemas que envolvam as operações de divisão e multiplicação.

Vejamos como proceder em nosso sistema de numeração utilizando a multiplicação praticada pelos egípcios.

Exemplo 1:

128.12

Precisaremos de duas colunas, onde na primeira coluna escreve-se 1 e na segunda o 12. O número 1 deve ser duplicado até obtermos 128 e 012 também deverá ser duplicado ao lado da coluna gerada pelo número 1 e seus resultados colocados ao lado de todos que foram obtidos na primeira coluna.

$\begin{array}{rlrl}1 & 12 \\ 2 & 24 & =12.2 \\ 4 & =2^{2} & 48 & =12.2^{2} \\ 8 & =2^{3} & 96 & =12.2^{3} \\ 16 & =2^{4} & 192 & =12.2^{4} \\ 32 & =2^{5} & 384 & =12.2^{5} \\ 64 & =2^{6} & 768 & =12.2^{6} \\ 128 & =2^{7} & 1536 & =12.2^{7}\end{array}$

Portanto $12.128=1536$.

Note que para efetuar essa multiplicação foi necessário apenas ter o conhecimento de como adquirir o dobro do número anterior.

\section{Exemplo 2: 84.15}

Do mesmo modo, escrevemos na primeira coluna 1 e a duplicaremos até alcançar 84 ou quando não possível duplicaremos até encontrar o menor número que mais se aproxime de 84, e na segunda coluna escrevemos o 15 e o duplicaremos colocando cada resultado obtido ao lado dos resultados obtidos na primeira coluna. 
1

2

$4=2^{2}$

$8=2^{3}$

$16=2^{4}$

$32=2^{5}$

$64=2^{6}$
15

$30=15.2$

$60=15.2^{2}$

$120=15.2^{3}$

$240=15.2^{4}$

$480=15 \cdot 2^{5}$

$960=15 \cdot 2^{6}$

Note que não alcançamos o 84 , portanto basta adicionar de forma conveniente termos na coluna 1 até adquirir 84 .

$(64+16+4)=84$. Assim, teremos:

$15.84=15 .(64+16+4)$

Aplicando a propriedade distributiva da multiplicação, temos que:

$15.84=960+240+60$

$15.84=1260$

\section{Justificativa Matemática}

Vamos verificar a multiplicação de $a$ por $b$.

$\begin{array}{rlrl}1 & b & =2^{0} \cdot b \\ 2 & 2 b & =2^{1} \cdot b \\ 4 & 4 b & =2^{2} \cdot b \\ 8 & 8 b & =2^{3} \cdot b \\ 16 & 16 b & =2^{4} \cdot b \\ 32 & 32 b & =2^{5} \cdot b \\ 64 & 64 b & =2^{6} \cdot b \\ 2^{\mathrm{n}} & 2^{\mathrm{n}} b\end{array}$

Note que é possível termos qualquer a somando termos pertencente a primeira coluna. 
Exemplo:

$2+4=6$, então:

$a=6$ e $a \cdot b=(2 b+4 b)$

Relacionando com a segunda coluna teremos pela soma dos produtos 0 resultado das multiplicações desejadas.

\subsubsection{Multiplicação hindu 1}

Objetivo: Esperamos que os alunos compreendam a idéia de cálculos praticados por outros povos e o significado das suas multiplicações.

Competência e habilidade: Multiplicação utilizando técnica alternativa.

Essa atividade [6] é direcionada as séries iniciais do ensino fundamental.

Exemplo:

28.325

\begin{tabular}{|l|r|r|r|}
\hline & 3 & 2 & 5 \\
\hline 2 & 8 & & \\
\hline
\end{tabular}

Multiplicamos 3 por 2, e o resultado é colocado na coluna acima do 2.

\begin{tabular}{|l|r|r|r|}
\hline 6 & 3 & 2 & 5 \\
\hline 2 & 8 & & \\
\hline
\end{tabular}

Multiplicamos 3 por 8 (que resulta 24), onde 4 ocupa a atual posição de 3 e 2 é adicionado ao 6 e 28 desloca-se uma casa para direita.

\begin{tabular}{|r|r|r|r|}
\hline 8 & 4 & 2 & 5 \\
\hline & 2 & 8 & \\
\hline
\end{tabular}

Na segunda coluna multiplicamos 2 por 2 e adicionamos ao 4 .

\begin{tabular}{|r|r|r|r|}
\hline 8 & 8 & 2 & 5 \\
\hline & 2 & 8 & \\
\hline
\end{tabular}

Multiplicamos na terceira coluna 2 por 8 (que resulta 16), o 6 ocupará o lugar do 2 e o 1 será adicionado ao 8 e 28 deslocará uma casa para direita. 


\begin{tabular}{|r|r|r|r|}
\hline 8 & 9 & 6 & 5 \\
\hline & & 2 & 8 \\
\hline
\end{tabular}

Multipliquemos na quarta coluna o 5 por 2 da terceira coluna, onde o 0 será adicionado a 6 e o 1 adicionado a 9.

\begin{tabular}{|r|r|r|r|}
\hline 9 & & 6 & 5 \\
\hline & & 2 & 8 \\
\hline
\end{tabular}

Multiplicamos na quarta coluna 8 por 5 , onde o 0 ocupará o lugar referente a 5 e 04 será adicionado ao 6.

\begin{tabular}{|r|r|r|r|}
\hline 9 & 1 & & \\
\hline & & 2 & 8 \\
\hline
\end{tabular}

Então 28 . $325=9100$, os zeros não aparecem, pois os hindus não utilizavam o zero ainda.

\section{Justificativa matemática}

Porque a multiplicação hindu funciona?

O princípio deste modo operatório consiste em proceder por tantas etapas quantas unidades existirem no multiplicando, correspondendo cada uma aos produtos de um número deste último pelos números sucessivos do multiplicador.

Primeira etapa:

$(3.2) \cdot 1000+(3 \cdot 8) \cdot 100$

Segunda etapa:

$(2 \cdot 2) \cdot 100+(2 \cdot 8) \cdot 10$

Terceira etapa:

$(5 \cdot 2) \cdot 10+(5 \cdot 8)$

\subsubsection{Multiplicação hindu 2}

Objetivo: Esperamos que os alunos compreendam a idéia de cálculos praticados por outros povos e o significado das suas multiplicações. 
Competência e habilidade: Cálculo da multiplicação utilizando técnica alternativa.

Essa atividade [6] é direcionada as séries iniciais do ensino fundamental.

Os conhecimentos abrangidos são os da multiplicação na perspectiva de dar aos educando uma nova visão da multiplicação de números inteiros possibilitando aos mesmos mais uma ferramenta de trabalho, ou seja, mais um modo de discutir problemas que envolva a operação da multiplicação.

Exemplo:

745.6538

A multiplicação de um número formado por 3 algarismo por um número formado por 4 algarismo precisará de um retângulo que tenha 3 linhas e 4 colunas.

\begin{tabular}{|c|l|l|l|l|}
\hline & 6 & 5 & 3 & 8 \\
\hline 5 & & & & \\
\hline 4 & & & & \\
\hline 7 & & & & \\
\hline
\end{tabular}

Cada pequeno retângulo deve ser cortado ao meio e o produto entre os dois números colocados no interior do mesmo.

\begin{tabular}{|l|l|l|l|l|l|}
\hline & & & 5 & 3 & 8 \\
\hline
\end{tabular}

Efetuando as adições das diagonais da esquerda para direita e levando a parte que se refere à dezena para a diagonal seguinte, temos: 
$1+2+2+3=8$

$1+3+4+2+5+2=7$

$1+0+2+0+1+1+5=0$

$1+5+1+2+3+6=8$

$5+4+2=1$

0

A soma dos valores compreendidos nas diagonais da direita para a esquerda resulta em:

$$
745.6538=4870810
$$

\section{Justificativa matemática}

Veja que temos no exemplo o produto de milhar por centena, onde o retângulo formado multiplica toda milhar respectivamente pelo algarismo da centena, algarismo da dezena e algarismo da unidade, cada produto resulta em um número de dois algarismos e a posição de cada produto pode representar unidade, dezena, centena, ... , por esse motivo que a adição entre as diagonais pode ser realizada.

\subsubsection{Jogo. Eu sei}

Objetivo: Saber aplicar seus conhecimentos sobre multiplicação e divisão de número inteiro em situações praticas.

Competência e habilidade: Cálculo mental envolvendo técnicas de divisão e multiplicação.

Essa atividade [15] é direcionada as séries iniciais do ensino fundamental.

Nessa atividade exploraremos a multiplicação através de um jogo simples, onde se leva em consideração que:

Os jogos constituem uma forma interessante de propor problemas, pois permitem que estes sejam apresentados de modo atrativo e favorecem a criatividade na elaboração de estratégias de resolução e busca de solução. Propiciam a simulação problema que exige soluções vivas e imediatas, o que estimula o planejamento das ações; possibilitam a construção de uma atitude positiva perante os erros, uma vez que as situações sucedem-se 
rapidamente e podem ser corrigidas de forma natural, no decorrer da ação sem deixar marcas negativas. [3]

Recursos: 11 cartas numeradas de -5 a 5 para cada jogador.

\section{Regras}

- Três jogadores, onde dois jogam e um é o juiz.

- Cada jogador embaralha suas cartas sem olhar.

- Os jogadores sentam-se de frente um para o outro de modo que o juiz veja a face dos dois.

- Ao sinal os jogadores pegam uma carta cada um e seguram junto ao rosto de modo que possa ver apenas a carta do adversário.

- O juiz anuncia o produto entre as cartas.

- Quem souber quais são as cartas anuncia "eu sei".

- Se acertar (ganhador) fica com as cartas.

- O jogo termina quando um jogador ficar com todas as cartas, mas também pode ser encerrado antes e o vencedor é quem tiver o maior número de cartas. 


\section{Capítulo 7}

\section{Introdução}

É notável que os alunos enriqueceram seus conhecimentos e conseqüentemente os objetivos foram alcançados, pois durante o desenvolvimento da proposta conseguimos rever as operações de divisão e multiplicação dentro dos moldes conhecidos e usualmente aplicados pelos educandos e também acrescentamos novas formas de dividir e multiplicar além da oportunidade de desenvolvermos ou revisarmos outros conceitos como: determinar o dobro,encontrar os divisores e combinação linear.

Notei que muito mais existe a ser explorado, mudanças podem ser acrescentadas a cada passo que se dá para tornar mais rica em conhecimento as atividades. Concluímos que podem ser inseridas de forma conveniente e planejadas: uso de ambientes dentro da escola que altere a rotina de sala de aula, troca de conhecimento entre os alunos, uso de material didático e jogos.

Cabe destacar que a troca de conhecimento entre os alunos, o envolvimento e a atenção foram fundamentais para que os objetivos fossem alcançados.

\section{Aplicações de atividades}

Descreveremos a aplicação de três atividades em sala de aula realizadas com alunos do $8^{\circ}$ ano do ensino fundamental e com alunos do $1^{\circ}$ ano do ensino médio. Nosso objetivo foi viabilizar a proposta desse trabalho ao inserir laboratórios de matemática e projetos relacionados com o estudo das operações de divisão e multiplicação.

\subsection{Descrições das atividades}

\subsubsection{Metodologia e desenvolvimento da aplicação}

Para aplicação das atividades participaram duas turmas sendo uma do $8^{\circ}$ ano do ensino fundamental e uma do $1^{\circ}$ ano do ensino médio e estas foram organizadas em sala de aula de maneira que os alunos com mais dificuldades interagissem com os de menos dificuldades para assim um auxiliar o outro na realização das tarefas proposta. As tarefas propostas eram compostas de atividades complementares que 
tradicionalmente não são realizadas em sala, a duração da aplicação de cada atividade foi de duas aulas de 50 minutos.

Imagens foram registradas do desenvolvimento dos discentes como podemos ver logo abaixo:

Figura $7.1: 8^{\circ}$ ano do ensino fundamental realizando atividade.
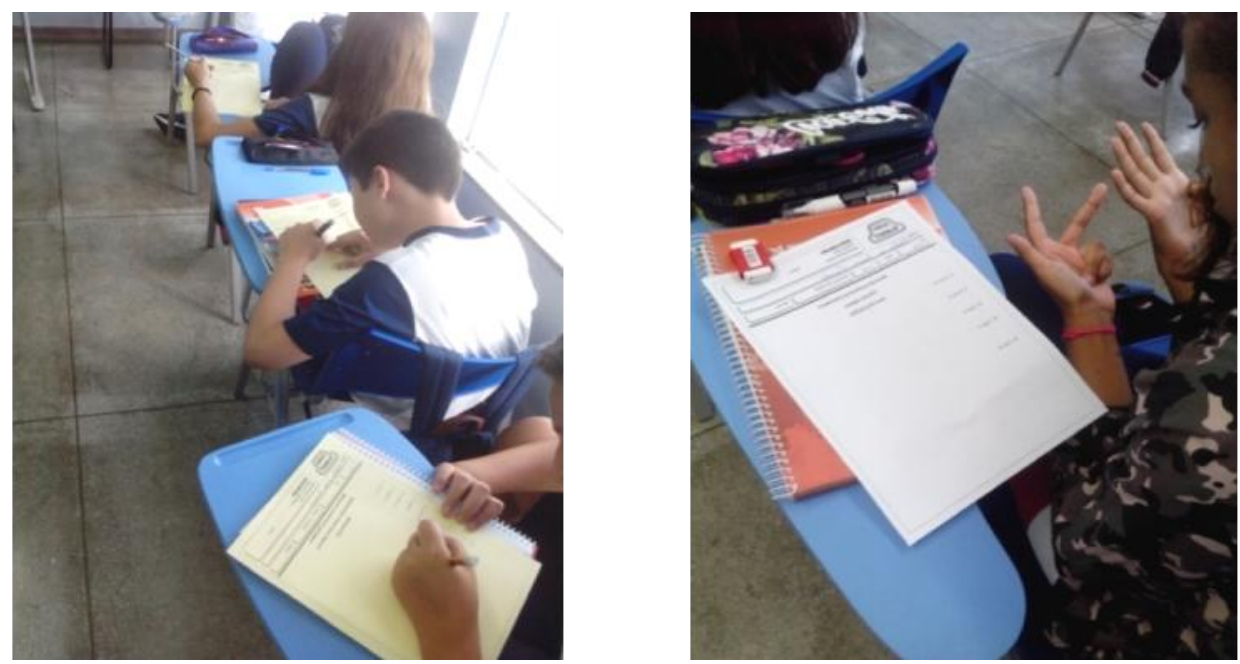

Fonte: O autor

Figura $7.2: 1^{\circ}$ ano do ensino médio realizando atividade.

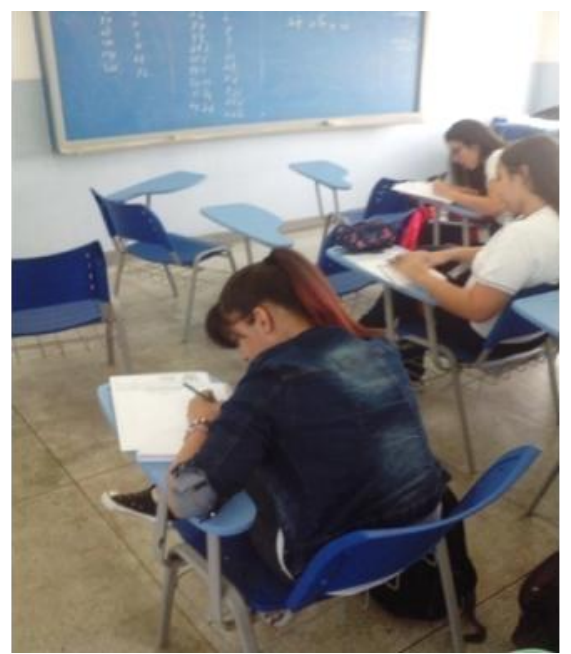

Fonte: O autor 
7.1.2 Atividade realizada pelos alunos do $1^{\circ}$ ano do ensino médio.

Objetivo

Trabalhar as definições e as operações fundamentais de divisão; reconhecer um número inteiro e também usá-lo para encontrar os divisores de certo número natural; aplicar o algoritmo da divisão; compreender o significado do dobro de um número e saber utilizar as diferentes formas de multiplicação de modo significativo.

Atividade 1 (Divisão usada pelos egípcios):

A aula foi iniciada revisando o método de divisão usual de números inteiros. A seguir apresentamos o algoritmo de Euclides que descreve o resto da divisão como combinação linear do dividendo e do divisor.

Em seguida foi exemplificada a divisão usada pelos egípcios. Nesta atividade, os alunos acharam interessante efetuar multiplicações apenas dobrando números e adicionando termos. Além disso, alguns alunos indagaram o quanto extenso é o método para algumas divisões.

Após estas discussões iniciamos a aplicação da atividade abaixo: 
Figura 7.3: Resultados: $1^{\circ}$ ano do ensino médio

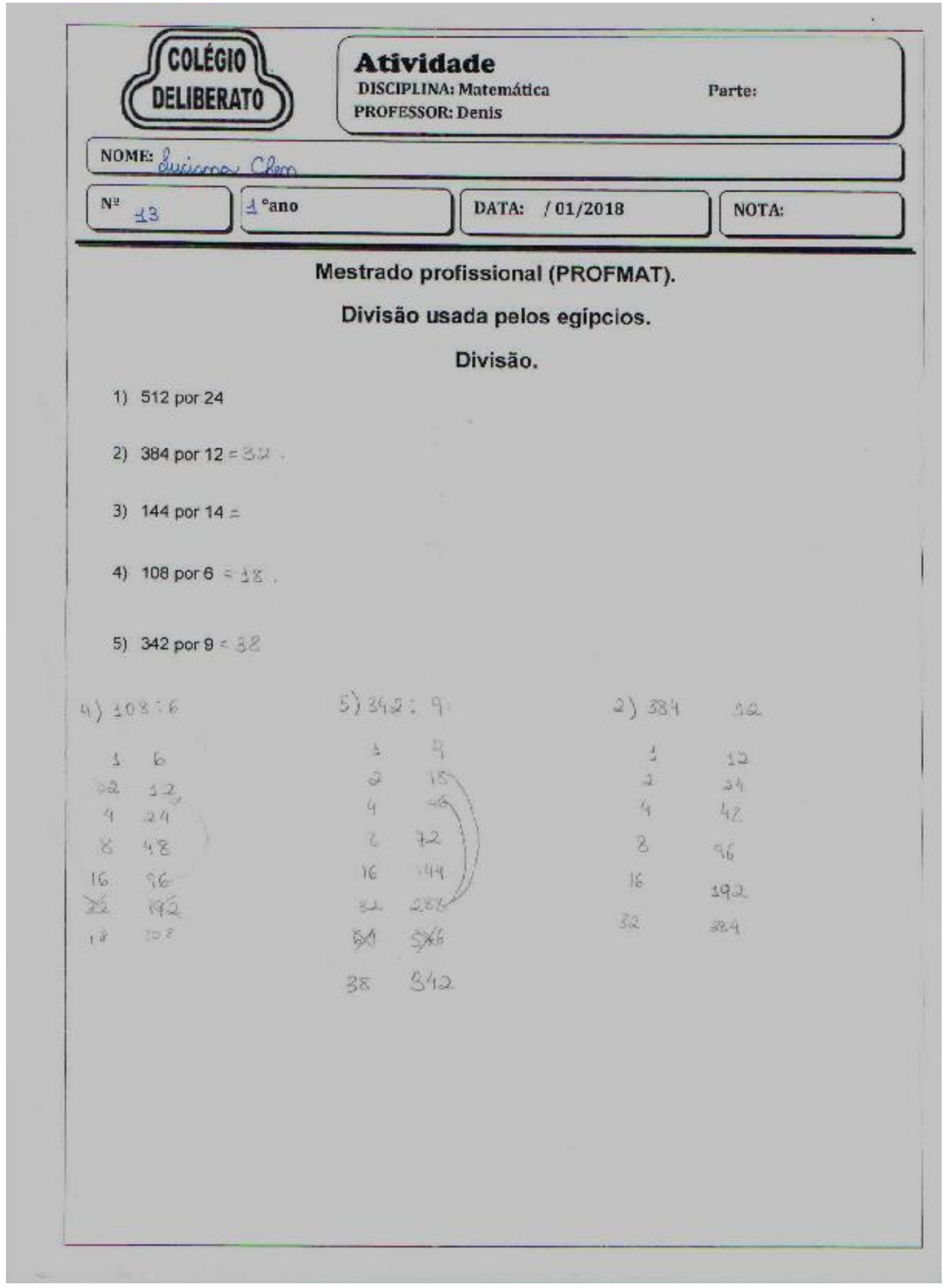

Fonte: $\mathrm{O}$ autor 
Por se tratar de uma turma experiente, poucas dificuldades apareceram durante a execução deste laboratório, pois eles se mostraram muitos hábeis com as operações de multiplicação e adição.

Podemos ainda ressaltar que um dos alunos ainda conseguiu perceber e divulgar aos outros que nem sempre é possível efetuar a divisão usando esse procedimento, pois dentre os exercícios propostos alguns deles não apresentava resolução adequada. Depois de questionado, o professor explicou aos alunos que esse processo de divisão se aplica apenas divisões exatas, assim não sendo possível obter êxito para divisões que deixam restos.

\subsubsection{Atividade realizada pelos alunos do $8^{\circ}$ ano do ensino fundamental.}

Objetivo

Trabalhar a compreensão e o significado do dobro de um número; Utilizar diferentes formas de multiplicações de modo significativo; Resolver situações problema recorrendo a raciocínios sem a necessidade de aplicações de fórmula ou memorizações.

Atividade 2. (Multiplicação usada pelos egípcios):

A aula foi iniciada com uma breve discussão sobre a origem desse método de multiplicação, onde seguimos com uma rápida revisão dos métodos utilizados atualmente. Toda turma foi desafiada pelo professor a resolver na lousa alguns exercícios que envolviam multiplicações para que pudessem demonstrar seus conhecimentos e suas habilidades, com a finalidade de diagnosticar o nível dos alunos, onde houve apenas dois candidatos que se mostraram hábeis em suas resoluções. Nesse momento foi apresentada como era efetuada a multiplicação usada pelos egípcios. O que causou grande apreensão, curiosidade e estranheza entre os alunos, por saber que é possível efetuar produtos sabendo apenas dobrar (multiplicar por 2) e adicionar valores, era nítido que aquele modo de resolução era diferente de todas as formas e meios que eles conheciam para realizar seus cálculos. 
Entretanto, todos se adaptaram rapidamente com o novo método após aplicálo em alguns exercícios básicos como podemos ver em uma das atividades realizada abaixo.

Figura 7.4: Resultados: $1^{\circ}$ ano do ensino médio

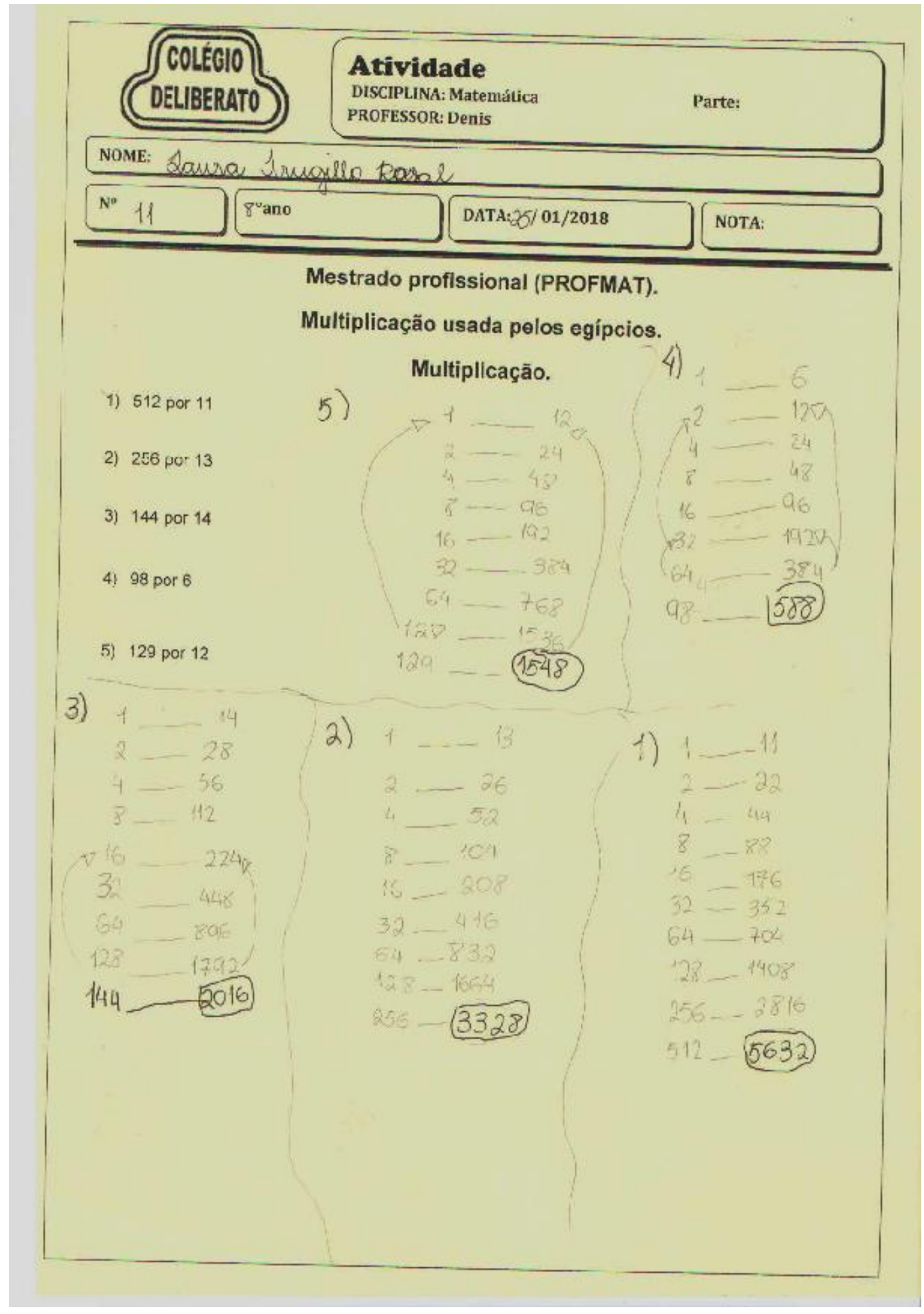

Fonte: $\mathrm{O}$ autor 
Durante a execução desse laboratório os alunos se ajudaram, pois o professor permitiu que os discentes se comunicassem, notava-se que aqueles com maior rendimento após encerrar sua atividade auxiliavam seus colegas ensinando o que aprendeu para que todos concluíssem o desafio.

Podemos destacar alguns comentários feitos pelos alunos durante a realização desta atividade: "É muito fácil, mas extenso", "Apesar de fácil prefiro fazer do meu jeito",... . Apesar algumas resistências todos os alunos concluíram a atividade.

Atividade 3. (Cálculos digitais):

Iniciamos esta atividade discutindo como atualmente os alunos fazem para realizar as multiplicações. No geral, quase todos se manifestaram respondendo que decoravam as tabuadas, mas acabavam por muitas vezes as esquecendo. Nesse momento, vi a oportunidade de propor um modo diferente de saber a tabuada e assim não mais seria necessário memorizar resultados.

Muitos alunos se mostraram entusiasmados, pois perceberam que se tratava de uma maneira prática e simples de multiplicar utilizando o novo método que thes ajudariam. Seguimos a aula discutindo algumas multiplicações onde a atenção dos alunos era intensa.

Quando o primeiro exemplo da multiplicação usando os dedos foi proposto, os alunos se envolveram reproduzindo o método e comentando: "Professor porque não ensinou isso antes?", "Agora eu não erro mais!", ... Ainda assim houve alguns alunos que apresentaram dificuldades, o professor interferiu dando a eles outras orientações e atendimento de forma independente, como também pediu a colaboração daqueles que apresentavam maior rendimento no auxilio as dificuldades de seus amigos, para que todos pudessem também desenvolver o laboratório, como podemos observar pela figura abaixo: 
Figura 7.5: Resultado: $8^{\circ}$ ano do ensino fundamental.

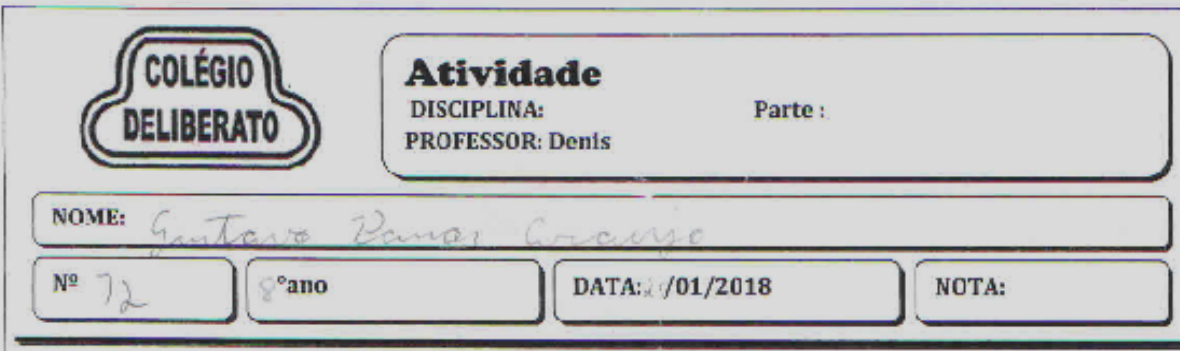

Mestrado profissional (PROFMAT)

Cálculos digitais.

MULTIPLICAÇÕES.

1) 6 por 8

48

2) 8 por 9

71

3) 5 por 6

20

4) 7 por 7

49

5) 9 por 8

7. 2

Fonte: $\mathrm{O}$ autor 


\section{Capítulo 8}

\section{Conclusões}

Discutiu-se a lenta evolução humana ao longo dos anos que registrou, acumulou informações e transformou seus registros matemáticos nas diversas formas de contar, nas bases e nos sistemas de numeração. Destacou-se o sistema posicional de numeração Hindu-Arábico de base 10 que se consagrou completo e eficiente após o surgimento do zero, permitindo a evolução da matemática levando a construção dos conjuntos.

Apresentou-se conjuntos dos números naturais e inteiros a fim de proporcionar um entendimento significativo desses conjuntos, portanto contribuindo com a base conceitual do aluno e auxiliando no desenvolvimento das atividades lúdicas aqui também chamada de laboratórios e projetos. Exploraram-se também os conceitos de números racionais e congruência para concluirmos com uma exposição dos processos operatórios das divisões e das frações.

Apresentaram-se atividades lúdicas que sirvam como estratégias, com o objetivo de promover a satisfação em relação à necessidade de aprendizagem dos alunos, pois atualmente a escola é questionada quanto aos seus métodos e resultados. Por esse motivo, o professor junto à escola é desafiado a melhorar o desempenho dos estudantes, sair da rotina, compreender o aluno, dar uma visão diferente a matemática, ensinar de maneira prática e simples e criar projetos sempre buscando despertar o interesse do aluno e assim resgatar a função da escola.

Com esse trabalho espero estar colaborando no desenvolvimento da prática docente e discente no desenvolvimento dessas atividades aqui citadas ou adaptações das mesmas, ampliando o interesse do estudante pela matemática. 


\section{REFERÊNCIAS BIBLIOGRÁFICAS}

[1] BIANCHINI, Edwaldo e H. PACCOLA. A matemática tem razão. Editora moderna. São Paulo, São Paulo, 1998.

[2] BORDENAVE, J.D. PEREIRA, A. M. Estrutura de ensino - aprendizagem. Editora Vozes Petrópolis, Rio de Janeiro, 2010.

[3] BRASIL, Diretrizes Curriculares Nacionais Gerais da Educação Básica / Ministério da Educação. Secretária da Educação Básica. Diretoria de Currículo e Educação Integral. Brasília: MEC,SEB,DICEI, 2013.

[4] ENZENSBERGER, Hans M. O diabo dos números. Editora Cia das letras. $7^{\mathrm{a}}$ reimpressão. Tradução Sergio Tellarolli. São Paulo, São Paulo, 1997.

[5] GUNDLACH, Bernard H. Números e numerais. Editora Atual. Tradução Hygino H. Domingues. $7^{a}$ reimpressão. São Paulo, São Paulo, 1992.

[6] IFRAH,Georges. Os números, a história de uma grande invenção. Editora Globo. $9^{a}$ edição. Tradução Stella M. de Freitas Senra. São Paulo, São Paulo, 1998.

[7] LORENZATO, Sérgio. O laboratório de ensino de matemática na formação do professor. Editora autores associados LTDA. Campinas, São Paulo, 2010.

[8] MATEMÁTICA RIO. Dispõe sobre divisão método longo. [acesso em 10 junho 2017]. Disponível em: http://www.youtube.com/matemáticario.

[9] MILIES, C. P. e S. P. COELHO. Números, uma introdução a matemática. Editora Usp. São Paulo, São Paulo, 2003.

[10] OLIVEIRA, Luis Carlos Gois de. Análise de erros cometidos pelos discentes do sétimo ano do ensino fundamental e do primeiro ano do ensino médio no estudo dos números racionais e na sua forma fracionária. 2017. 97p. Dissertação (mestrado) - Universidade Federal de Sergipe - UFA, Itabaiana, 2017.

[11] PROGRAMA DE INICIAÇÃO CIENTIFICA DA OBMEP. Dispõe sobre problemas com calendário. [acesso em 5 janeiro 2018]. Disponível em: http://www.youtube.com/ProgramadeiniciaçãocientificadaOBMEP. 
[12] RAMOS, Faraco. Frações sem mistério. Editora Ática. $1^{\text {a }}$ edição. São Paulo, São Paulo, 2011.

[13] S. FOMIM. Sistema de numeração. Editora atual e editora Mir. $3^{\mathrm{a}}$ edição. Traduzido por Gelson lezzi. São Paulo, São Paulo, 1995.

[14] SKOVSMOSE, Ole. Desafios da reflexão em educação matemática crítica. Editora Papirus. Tradução Orlando de Andra Figueiredo e Jonei Cerqueira Barbosa. Campinas, São Paulo, 2008.

[15] SMOLE, K. S., M. I. DINIZ e E. MILANI. Caderno do mathema (jogos de matemática). Editora Artmed. Porto Alegre, Santa Catarina, 2007.

[16] Souza, Júlio Cezar de Melo. Matemática divertida e curiosa. Editora Record LTDA. Rio de janeiro, São Paulo 2008.

[17] STEWART, lan. Mania de matemática, diversão e jogos de lógica matemática. Editora Zahar. Tradução Maria Luiza X. de A. Borges. Rio de Janeiro, Rio de janeiro, 2005. 